\title{
A hydrometeorological model intercomparison as a tool to quantify the forecast uncertainty in a medium size basin
}

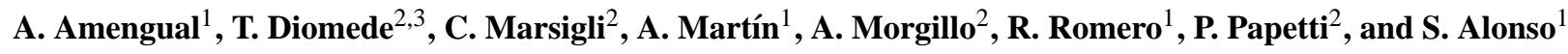 \\ ${ }^{1}$ Grup de Meteorologia, Departament de Física, Universitat de les Illes Balears, Palma de Mallorca, Spain \\ ${ }^{2}$ ARPA-SIM Servizio IdroMeteorologico dell'Emilia-Romagna, Bologna, Italy \\ ${ }^{3}$ Centro Interuniversitario di Ricerca in Monitoraggio Ambientale (CIMA), Università degli studi di Genova e della \\ Basilicata, Savona, Italy
}

Received: 4 December 2007 - Revised: 2 April 2008 - Accepted: 4 July 2008 - Published: 5 August 2008

\begin{abstract}
In the framework of AMPHORE, an INTERREG III B EU project devoted to the hydrometeorological modeling study of heavy precipitation episodes resulting in flood events and the improvement of the operational hydrometeorological forecasts for the prediction and prevention of flood risks in the Western Mediterranean area, a hydrometeorological model intercomparison has been carried out, in order to estimate the uncertainties associated with the discharge predictions. The analysis is performed for an intense precipitation event selected as a case study within the project, which affected northern Italy and caused a flood event in the upper Reno river basin, a medium size catchment in the EmiliaRomagna Region.

Two different hydrological models have been implemented over the basin: HEC-HMS and TOPKAPI which are driven in two ways. Firstly, stream-flow simulations obtained by using precipitation observations as input data are evaluated, in order to be aware of the performance of the two hydrological models. Secondly, the rainfall-runoff models have been forced with rainfall forecast fields provided by mesoscale atmospheric model simulations in order to evaluate the reliability of the discharge forecasts resulting by the one-way coupling. The quantitative precipitation forecasts (QPFs) are provided by the numerical mesoscale models COSMO and MM5.
\end{abstract}

Furthermore, different configurations of COSMO and MM5 have been adopted, trying to improve the description of the phenomena determining the precipitation amounts. In particular, the impacts of using different initial and boundary conditions, different mesoscale models and of increasing the horizontal model resolutions are investigated. The accuracy of QPFs is assessed in a threefold procedure. First, these

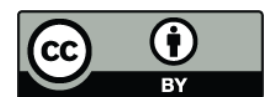

Correspondence to: A. Amengual (arnau.amengual@uib.es) are checked against the observed spatial rainfall accumulations over northern Italy. Second, the spatial and temporal simulated distributions are also examined over the catchment of interest. And finally, the discharge simulations resulting from the one-way coupling with HEC-HMS and TOPKAPI are evaluated against the rain-gauge driven simulated flows, thus employing the hydrological models as a validation tool.

The different scenarios of the simulated river flows - provided by an independent implementation of the two hydrological models each one forced with both COSMO and MM5 - enable a quantification of the uncertainties of the precipitation outputs, and therefore, of the discharge simulations.

Results permit to highlight some hydrological and meteorological modeling factors which could help to enhance the hydrometeorological modeling of such hazardous events. Main conclusions are: (1) deficiencies in precipitation forecasts have a major impact on flood forecasts; (2) large-scale shift errors in precipitation patterns are not improved by only enhancing the mesoscale model resolution; and (3) weak differences in flood forecasting performance are found by using either a distributed continuous or a semi-distributed eventbased hydrological model for this catchment.

\section{Introduction}

The AMPHORE project was a European INTERREG III B Programme mainly devoted to the hydrometeorological modeling study of heavy precipitation episodes resulting in flood events and the improvement of the operational hydrometeorological forecasts for the prediction and prevention of flood risks in the Western Mediterranean area. This project was the continuation of the previous HYDROPTIMET INTERREG III B European research project (further information in the NHESS special issue, HYDROPTIMET, Editor(s):

Published by Copernicus Publications on behalf of the European Geosciences Union. 
A. Buzzi, M. C. Llasat, C. Obled, and R. Romero, 2005). The Regional Hydrometeorological Service of Emilia-Romagna ARPA-SIM (Italy) and the Group of Meteorology of the University of the Balearic Islands (Spain) are two of the associated partners to this project. Within the AMPHORE framework, a set of hydrometeorological model simulations has been performed in order to improve the description of the phenomena determining the high precipitation amounts and to estimate the uncertainties associated with the hydrometeorological chain predictions. At this aim, this work focuses on one of the case studies selected in the project, an intense precipitation episode which affected northern Italy and caused a flood event over the upper Reno river basin, a medium-sized catchment in the Emilia-Romagna Region.

One of the more important challenges for numerical weather modeling is to improve the quantitative precipitation forecasts (QPFs) for hydrological purposes. Concretely, the reliability and practical use of the flood forecasting system for the upper Reno river basin is strongly connected with the accuracy of QPFs provided by numerical weather prediction (NWP) models. These are useful to extend the desired forecast lead time beyond the concentration time of the basin. In fact, for the upper Reno river basin, rainfall observations are not appropriate to drive the hydrological models, since they do not allow for the timely predictions required to implement an adequate emergency planning. The use of QPFs provided by NWP models is, therefore, fundamental. In general, the required lead times can range from several days ahead (for qualitative early warning) to 1-2 days (for flood warning and alarm) and down to a few hours for crisis management (Obled et al., 2004). This additional gain in lead time can be achieved only by including precipitation information ahead of its occurrence.

Nowadays, high-resolution numerical meteorological models - run with horizontal grid resolution of a few kilometres - are used to predict weather operationally. In addition, many studies dealing with the coupling of meteorological and hydrological models have shown that the scale compatibility does not seem to represent any longer a serious problem for a successful model coupling. These studies show that non-hydrostatic mesoscale models, run either in a research or operational mode, are able to provide realistic rainfall distributions for hazardous heavy precipitation episodes and aim at supplying a useful support for flood forecasting based on deterministic rainfall forecasts (Todini, 1995; Butts, 2000; Gerlinger and Demuth, 2000; Ranzi et al., 2000; Ducrocq et al., 2002; Bacchi and Ranzi, 2003; Benoit et al., 2003; Kunstmann and Stadler, 2004; Tomassetti et al., 2005; Amengual et al., 2007). Other studies propose to use a coupled atmospheric-hydrological model system as an advanced validation tool for the mesoscale simulated rainfall amounts (Benoit et al., 2000; Jasper and Kaufmann, 2003; Chancibault et al., 2006).
All the aforementioned experiences show that, despite current limitations, such approach has a great potential in flood forecasting and water resource management, representing also an additional level of verification useful for the improvement of atmospheric models. Most of the operational runoff forecasting systems are based on deterministic hydrometeorological chains, which do not quantify the uncertainty in the outputs. But, the flood forecasting process comprises several sources of uncertainty, which lies in the hydrological and meteorological model formulations, including the initial and boundary conditions, and in the gap which is still present between the scales resolved by the two systems as well. Furthermore, QPFs in extreme events are a remarkably arduous task because many factors concur in its determination, especially for intense and localised rainfall. NWP models have also problems in triggering and organizing convection over the correct locations and times due to the smallscale nature of many responsible atmospheric features and to their imperfect representation within these models (Tribbia and Baumhefner, 1988; Kain and Fritsch, 1992; Stensrud and Fritsch, 1994a and b).

Within the HYDROPTIMET project framework, some works were addressed to the study of these uncertainties through a numerical meteorological model intercomparison. For example, Anquetin et al. (2005) analyzed the 89 September 2002 flood occurred in the Gard region, France; and Mariani et al. (2005) studied the 9-10 June 2000 flashflood episode in Catalonia, Spain. The former work aimed at an improvement of QPFs to be relevant for hydrological modeling purposes, and the latter study was devoted to draw more conclusions of the model factors which can give a good forecast for these kinds of events. Both studies pointed out that high-resolution modeling is an important issue to address for a successful prediction of convectively-driven episodes bearing high amounts of precipitation. However, these works also found the aforementioned problems on the precise location and timing of the simulated precipitation patterns and an underestimation on the rainfall amounts by the limited area models as well.

In this context, the present study aims at highlighting some meteorological and hydrological factors which could enhance the hydrometeorological modeling of such hazardous events. At this purpose, we evaluate through a model intercomparison the uncertainties owing to two different sources which directly affect hydrometeorological modeling: one arising from the errors in the QPFs provided by a mesoscale meteorological model and the other arising from the errors in the hydrological model formulation. The first is, in turn, due to errors in the initial and boundary conditions, to the limited vertical and horizontal resolutions adopted, to the nesting strategy used to drive the model and to the formulation of the model itself. In order to take into account the meteorological model error, two different nonhydrostatic limited-area mesoscale models have been used: (i) the COSMO model (previously known as Lokal Modell) 
and; (ii) the fifth-generation Pennsylvania State UniversityNCAR Mesoscale Numerical (MM5) model.

The other sources of error affecting the QPFs have been considered by using different initial and boundary conditions and by changing the models' resolution. Furthermore, it has been used two different nesting techniques: COSMO and MM5 have been run in a one-way and a two-way nesting mode, respectively. In the one-way nesting, the information is interpolated from the coarse to the fine grid without feedback from the fine grid. The two-way nesting allows a feedback upscale of the small-scale features from the fine to the coarse domain, and therefore, it influences the features in the large-scale (Zhang and Fritsch, 1986). Even though a two-way interaction is believed to work better, it may introduce instabilities at the interface between the two grids which may degrade the solution (Zhang et al., 1986). Therefore, both nesting techniques could lead to rather different results on the simulated precipitation fields when applied to a mesoscale episode with marked dynamic forcing and over a region with such complex sea-land and orographic distributions as northern Italy.

On the other hand, in order to consider also the part of the uncertainty coming from the hydrological model formulation, two different rainfall-runoff models have been considered, even though the choice of the one most appropriate model for any specific task is difficult (Todini, 2007). The two models are: (i) the physically-based Hydrologic Engineering Center's Hydrologic Modeling System (HEC-HMS) model - run in a semi-distributed and event-based configuration - and; (ii) the distributed and physically-based TOPographic Kine-matic APproximation and Integration (TOPKAPI) model - run in a continuous way. These models have been implemented over the upper Reno river basin and differ in their physical parameterizations and structure. Concretely, their different physical descriptions of the soil infiltration mechanism are of particular interest in this work. This aspect influences the simulated basin's response strongly, since it determines the modeled soil moisture content. An accurate quantification of the initial state of this variable before the occurrence of a flood event is fundamental for a reliable hydrological model forecast.

For practical hydrological predictions there are important benefits in exploring different hydrological model structures (Butts et al., 2004). As a matter of fact, this approach enable to examine the impact of model structure error and complexity on the flood forecasting chain and to extend the assessing of modelling uncertainty involved in the meteo-hydrological coupling. In the hydrological literature, recent studies have investigated the use of different models, in particular with respect to the effects of model structure in the context of modelling performance and to consider in a more comprehensive way uncertainty in model structure (Refsgaard and Knudsen, 1996; Atkinson et al., 2002 and 2003; Farmer et al., 2003; Butts et al., 2004; Georgakakos et al., 2004; Koren et al., 2004; Hearman and Hinz, 2007).

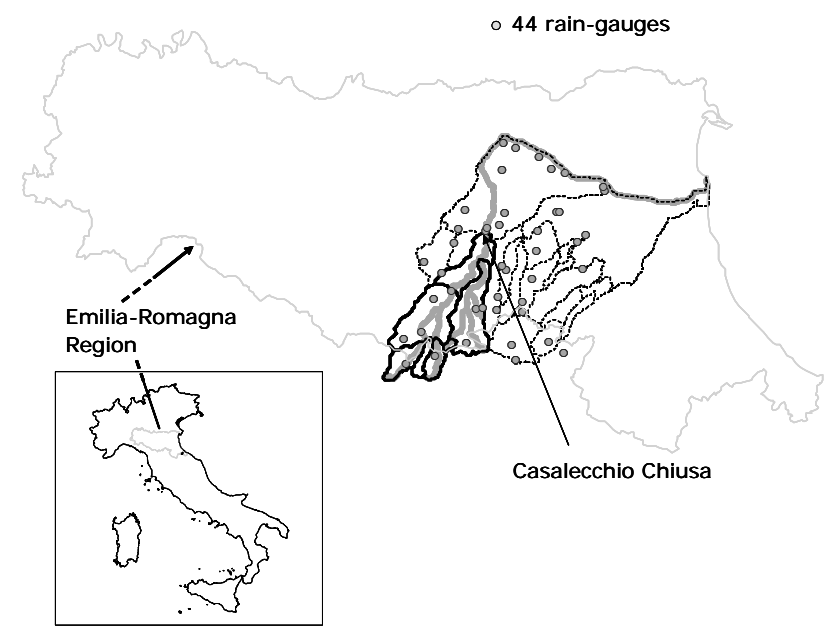

Fig. 1. Localisation of the Reno river basin in the Emilia-Romagna Region (grey line), northern Italy, its sub-catchments (dashed black lines, in evidence the upper basin closed at Casalecchio Chiusa as thick black line) and the main river (thick grey line). Dots denote the 44 rain-gauges present in the basin.

Regarding the aim of the present work, the use of two models with different structures, especially for the modelling of the soil infiltration mechanism, may result beneficial to better understand and describe the rainfall-runoff transformation processes, according to the nature of the rainfall episode which occur over the catchment in question. As a matter of fact, the characteristics of the rainfall event (i.e. spatial-temporal distribution and intensity) may influence the simulated catchment's response depending on the modelled surface runoff generating mechanism (Hearman and Hinz, 2007).

The accuracy of the simulations provided by the proposed hydrometeorological experiments is assessed by means of a threefold approach. First, the experiments have been evaluated by comparing the spatial observed and simulated rainfall accumulations through a point validation methodology using categorical verification statistics. Second, the performance of the spatial and temporal distributions of the QPFs over the upper Reno river basin has been examined by using continuous verification indices. Finally, it has also been analyzed the simulated discharges which result from the oneway coupling with the NWP models in the catchment of interest. Thus, the hydrological models are employed also as a validation tool for the QPFs. To fulfil this aim, the streamflows obtained by using observed rainfall data as input have been used as reference values for the comparison with the results derived from the mesoscale models driven runoff simulations. In this way, systematic errors of the hydrological models would not affect the comparison. 
The paper is structured as follows: Sect. 2 contains a brief description of the study area and of the selected intense rainfall episode; Sect. 3 describes the hydrological models used for the basin characterization; Sect. 4 describes the numerical meteorological models; Sect. 5 presents and discusses the results; and finally, Sect. 6 provides an assessment of the proposed methodology as well as future directions for its further development.

\section{Descriptions of the area of interest and the event}

\subsection{The watershed of interest}

The Reno river basin is the largest in the Emilia-Romagna Region, northern Italy, measuring $4930 \mathrm{~km}^{2}$ (Fig. 1). It extends about $90 \mathrm{~km}$ in the south-north direction, and about $120 \mathrm{~km}$ in the east-west direction, with a main river total length of $210 \mathrm{~km}$. Slightly more than half of the area is part of the mountain basin. The basin is divided into 43 sub-catchments. The mountainous part, crossed by the main river, covers $1051 \mathrm{~km}^{2}$ up to Casalecchio Chiusa, where the river reaches a length of $84 \mathrm{~km}$ starting from its springs (Fig. 1). This upper catchment extends about $55 \mathrm{~km}$ in the south-north direction, and about $40 \mathrm{~km}$ in the east-west direction. It follows a foothill reach about $6 \mathrm{~km}$ long, characterised by a particular hydraulic importance since it has to connect the regime of mountain basin streams with the river regime of the leveed watercourse in the valley. Contributing to the importance of this reach is the fact that it extends practically to within the city limits of Bologna. Then, the valley reach conducts the waters (enclosed by high dikes) to its natural outlet in the Adriatic Sea, flowing along the plain for $120 \mathrm{~km}$. In the valley reach, the transverse section of the Reno river is up to about $150-180 \mathrm{~m}$ wide. The altitude of $44 \%$ of the area is below $50 \mathrm{~m}, 51 \%$ is characterized by an altitude from $50 \mathrm{~m}$ up to $900 \mathrm{~m}$, and the remaining $5 \%$ is between 900 and $1825 \mathrm{~m}$.

The concentration time of the watershed is about 10-12 h at the Casalecchio Chiusa river section and about $36 \mathrm{~h}$ when the flow propagates through the plain up to the outlet. In this work, the observed and simulated discharges are evaluated at Casalecchio Chiusa, the closure section of the mountainous basin (hereafter "Reno river basin" refers only to this upper zone of the entire watershed). In practice, a flood event at such a river section is defined when the water level, recorded by the gauge station, reaches or exceeds the value of $0.8 \mathrm{~m}$ (in terms of discharge, a value of about $80 \mathrm{~m}^{3} \mathrm{~s}^{-1}$ ), corresponding to the warning threshold. The pre-alarm level is set to $1.6 \mathrm{~m}$ (corresponding to a discharge value of about $\left.630 \mathrm{~m}^{3} \mathrm{~s}^{-1}\right)$.

\subsection{The 7-10 November 2003 event}

On 6 November at about 00:00 UTC, an upper level deep trough at the level of $500 \mathrm{hPa}$ is active over Northern Eu- rope and moves towards south-west interesting the Balcanic area, evolving into a cut-off low in the following hours (not shown). On 00:00 UTC 7 November this cyclonic vortex moved backward from the Adriatic sea and in the following $12 \mathrm{~h}$ reached the Alpine region (Fig. 2). During the evening the cyclone continues to move backward and the upper level winds tend to become southerly. Starting from the evening of 7 November, intense precipitation occurred over the central part of the Apennine chain, especially over the Reno river basin, with presence of large amounts of snowfall over the western Apennine even at moderate altitude (less than $500 \mathrm{~m}$ ). The persistence of southerly upper level winds determines on the following morning a rapid increase of temperature. On November 8th, thundery cells develop over Tuscany and determine intense precipitation over the central part of the Apennine chain, in particular over the hydrographic basin of the Panaro and Reno rivers.

During the whole 48-h event (Fig. 3), a widespread precipitation was observed over northern Italy. Intense rainfall interested the whole Emilia-Romagna Region and the north-eastern part of Italy, with several station recording values up to $100 \mathrm{~mm}$ in $48 \mathrm{~h}$. Maximum values of about 150 $200 \mathrm{~mm} / 48 \mathrm{~h}$ were reached over the central Apennine, on the upper part of the Reno river basin. The maximum water level at Casalecchio Chiusa was $1.75 \mathrm{~m}$ (corresponding to a discharge value of about $760 \mathrm{~m}^{3} \mathrm{~s}^{-1}$ ), at 20:00 UTC, 8 November, representing the 13 th most critical case in terms of flood event magnitude over a historical archive of 90 events from 1981 to 2004.

\section{The hydrological models}

The hydrometeorological model intercomparison study proposed in the present work is carried out by using two different physically-based rainfall-runoff models to generate simulated discharges. These are: (i) HEC-HMS; (USACE-HEC, 1998) and; (ii) TOPKAPI (Todini and Ciarapica, 2002).

\subsection{HEC-HMS model}

The model has been implemented in a semi-distributed and event-based configuration. HEC-HMS utilizes a graphical interface to build the semi-distributed watershed model and to set up precipitation and control variables for the simulations. At this aim, Fig. 4 depicts the digital elevation map (DEM) used, with a cell resolution of $500 \mathrm{~m}$, and the main watercourses forming the upper Reno river catchment. The whole basin has been segmented in 13 subbasins with an average size of $83.6 \mathrm{~km}^{2}$.

The hydrological model is forced by using a single hyetograph for each subbasin. Rainfall spatial distributions were first generated from hourly values recorded at the automatic rain-gauge stations by applying the kriging method with a horizontal grid resolution of $500 \mathrm{~m}$. Then, the hourly rainfall 



Fig. 2. ECMWF analyses of the geopotential height at $500 \mathrm{hPa}$ (contours in continuous black line) and of temperature at $850 \mathrm{hPa}$ (contours in dash grey line) every $12 \mathrm{~h}$ from 00:00 UTC 7 November 2003 to 12:00 UTC 8 November 2003.

series were calculated for each subbasin as the area-averaged of the gridded precipitation within the subcatchment. The same methodology is used to assimilate forecast precipitation fields in HEC-HMS, except the atmospheric model grid points values are used instead of pluviometric observations. The kriging analysis method has been used by applying a linear model for the variogram fit. This minimal error variance method is recommended for irregular observational networks and has been commonly used to compute rainfall fields from rain-gauges (Krajewski, 1987; Bhagarva and Danard, 1994; Seo, 1998).

The rainfall-runoff model calculates runoff volumes by using the Soil Conservation Service Curve Number method (SCS-CN; US Department of Agriculture, 1986). A synthetic unit hydrograph (UH) model also provided by SCS is used to convert precipitation excess into direct runoff. Baseflow is calculated by means of an exponential recession method which explains the drainage from natural storage in the watershed (Linsley et al., 1982). Flood hydrograph is routed using the Muskingum method (Chow et al., 1988). As the model has been here implemented in a semi-distributed configuration, the hydrological processes that are lead by the slope are resolved by means of lumped parameters for each subbasin.

The hydrological model has been calibrated during the 2002-2003 period. Within this period, three events were considered the most suitable to perform the model calibration owing to their similar characteristics to our case study. The similarity is intended in terms of: the antecedent soil conditions, the characteristics of the rainfall event driving to intense precipitation rates in short time scales, and the notable amplitude of the subsequent peak discharges (all of them exceeded $300 \mathrm{~m}^{3} \mathrm{~s}^{-1}$ ). Calibration of the infiltration parameters for each independent episode combines a manual procedure, where the SCS curve numbers -and therefore, the initial abstractions- are derived from the land uses and soil cover properties of the basin under normal antecedent moisture conditions, and an automatic procedure. This automatic 
Table 1. Summary of the main characteristics for the adopted meteorological models configurations.

\begin{tabular}{|c|c|c|c|c|c|c|c|}
\hline Experiment & Model & $\begin{array}{r}\text { Horizontal } \\
\text { resolution } \\
(\mathrm{km})\end{array}$ & $\begin{array}{l}\text { Grid } \\
\text { points }\end{array}$ & Levels & $\begin{array}{l}\text { Initial and } \\
\text { boundary } \\
\text { conditions }\end{array}$ & Assimilation & $\begin{array}{l}\text { Nesting } \\
\text { procedure }\end{array}$ \\
\hline $\begin{array}{l}\text { COSMO hind }+ \text { obs } 7 \\
\text { (control) }\end{array}$ & COSMO & 7 & $234 \times 272$ & 36 & ECMWF analyses & continuous & 1-way \\
\hline COSMO hind 7 & COSMO & 7 & $234 \times 272$ & 36 & ECMWF analyses & No & 1-way \\
\hline COSMO hind 2.8 & COSMO & 2.8 & $265 \times 270$ & 36 & $\begin{array}{l}\text { COSMO hind } 7 \text { analyses } \\
\text { and forecasts }\end{array}$ & No & 1-way \\
\hline $\operatorname{COSMO} f_{c} 7$ & COSMO & 7 & $234 \times 272$ & 36 & $\begin{array}{l}\text { COSMO analysis and } \\
\text { ECMWF forecasts }\end{array}$ & No & 1-way \\
\hline COSMO fc 2.8 & COSMO & 2.8 & $265 \times 270$ & 36 & $\begin{array}{l}\text { COSMO fc } 7 \text { analysis } \\
\text { and forecasts }\end{array}$ & No & 1-way \\
\hline $\begin{array}{l}\text { MM5 hind }+o b s \\
(\text { control at } 7.5 \mathrm{~km})\end{array}$ & MM5 & $\begin{array}{l}7.5 \\
2.5\end{array}$ & $151 \times 151$ & 24 & ECMWF analyses & continuous & 2-way \\
\hline MM5 hind & MM5 & $\begin{array}{l}7.5 \\
2.5\end{array}$ & $151 \times 151$ & 24 & ECMWF analyses & No & 2-way \\
\hline$M M 5 f c$ & MM5 & $\begin{array}{l}7.5 \\
2.5\end{array}$ & $151 \times 151$ & 24 & $\begin{array}{l}\text { ECMWF analysis } \\
\text { and forecasts }\end{array}$ & No & 2-way \\
\hline
\end{tabular}

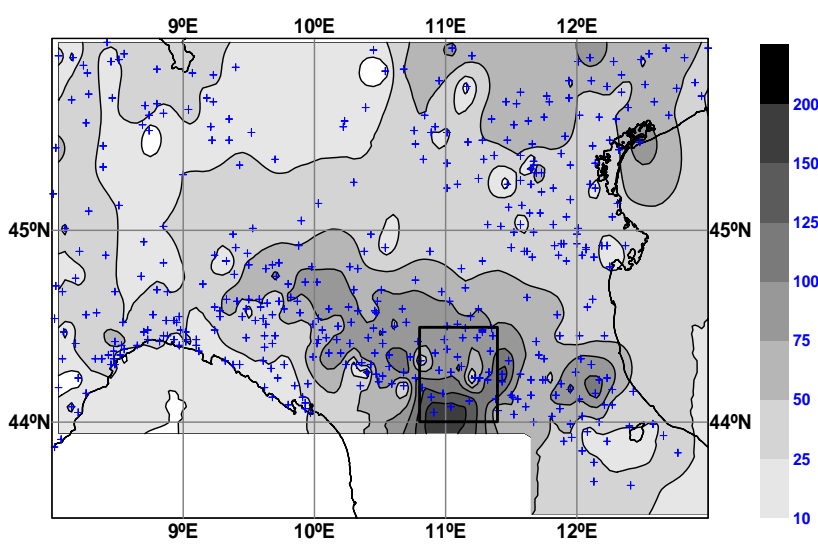

Fig. 3. Accumulated observed precipitation (in mm according to the scale) from 13:00 UTC 7 November 2003 to 12:00 UTC 9 November 2003, over an area covering northern Italy. The area of the upper Reno river basin is included within the black rectangle. Blue crosses denote the 579 rain-gauges available over the domain. Kriged observed precipitation has been blanked in the areas without raingauge information in order to avoid artificial rainfall distributions.

procedure uses as objective function the peak-weighted rootmean-square error and applies the univariate-gradient search algorithm method (USACE-HEC, 2000). In addition, for the main streams, the flood wave celerity is also considered as a calibration index - by means of the $K$ parameter - due to the nature of these kinds of episodes characterized by high flow velocities, besides the baseflow recession parameters. Then, the rainfall-runoff model is run in a single evaluation simulation for the 7-10 November 2003 episode. This simulation lasts $84 \mathrm{~h}$ from 12:00 UTC on 7 November 2003 to

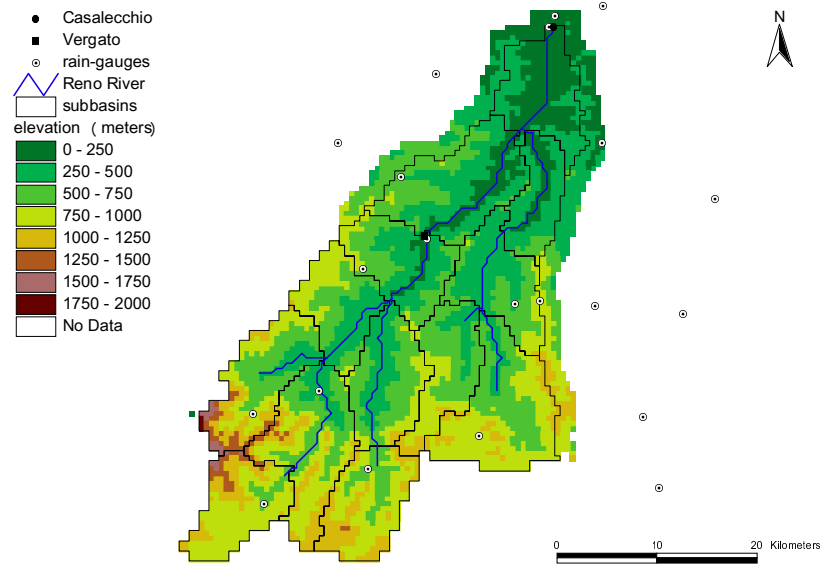

Fig. 4. Digital elevation model (DEM) of the upper Reno river basin. It displays the basin division defined in the implementation of the HEC-HMS model; the main watercourses; the automatic pluviometric stations over or nearby the watershed (dotted circles); and the flow-gauge (black circle) closing the basin at Casalecchio outlet.

00:00 UTC on 11 November 2003, with a time-step interval of $1 \mathrm{~h}$. This period completely encompasses the flood event and the subsequent hydrograph tail. All the mesoscale model driven runoff experiments are run for the same time window.

\subsection{TOPKAPI model}

This model couples the kinematic approach with the topography of the catchment and transfers the rainfall-runoff processes into three "structurally-similar" zero-dimensional non-linear reservoir equations. Such equations derive from the integration in space of the non-linear kinematic wave 
model: the first represents the drainage in the soil, the second represents the overland flow on saturated or impervious soils and the third represents the channel flow. The parameter values of the model are shown to be scale independent and obtainable from DEM, soil maps and vegetation or land-use maps in terms of slopes, soil permeabilities, topology and surface roughness. A detailed description of the model can be found in Liu and Todini (2002).

For the implementation of the model over the Reno river basin, the grid resolution is set to $500 \times 500 \mathrm{~m}$. This size of the grid cell, which represents a computational node for the mass and momentum balances, can be considered appropriate to take into account all the hydrological processes that are mainly lead by the slope. As a matter of fact, a correct integration of the differential equations from the point to the finite dimension of a pixel, and from the pixel to larger scales, can actually generate relatively scale independent models, which preserve, as averages, the physical meaning of the model parameters (Liu and Todini, 2002). This consideration is reflected in the TOPKAPI approach.

The calibration and validation runs have been performed forcing the model in a continuous way with the hourly rainfall and temperature data observed from 1990 to 2000 over the Reno river basin. The calibration process did not use a curve fitting process. Rather, an initial estimate for the model parameter set was derived using values taken from the literature. Then, the adjustment of parameters was performed according to a subjective analysis of the discharge simulation results. The simulation runs performed for the present work have been carried out exploiting different techniques to spatially distribute the precipitation data (forecasts and rain-gauge observations) onto the hydrological model grid. A Block Kriging technique, developed by Mazzetti and Todini (2004), was applied to interpolate the irregularly distributed surface observations. Within the framework of this approach, once the semi-variogram model has been defined (the Gaussian model in this case), the computation of the parameters of the Semi-variogram function is updated at each time step using a Maximum Likelihood estimator (Todini, 2001). On the other hand, the rainfall fields predicted by COSMO-LAMI were downscaled to each pixel of the hydrological model structure by assigning to the value of the nearest atmospheric model grid point.

\section{The meteorological models}

The non-hydrostatic COSMO and MM5 limited-area models are used to perform the meteorological simulations. Table 1 briefly summarizes the different models' experiments, with their main characteristics such as initial and boundary conditions, the nesting technique, the number of vertical levels and the models' horizontal resolutions. The model integration domains are shown in Fig. 5.

\subsection{COSMO model}

The COSMO model (previously known as Lokal Modell) was originally developed at the DWD (Deutscher WetterDienst) (Steppeler et al., 2003) and it is currently developed and maintained by the COSMO Consortium (COnsortium for Small-scale Modelling), which involves Germany, Italy, Switzerland, Greece, Poland and Romania.

COSMO is a non-hydrostatic model, based on the primitive equations describing fully compressible non-hydrostatic flow in a moist atmosphere, without any scale approximation. The model equations are expressed with 5 prognostic variables: temperature, pressure, humidity, horizontal and vertical velocity components. They are solved numerically using the traditional finite difference method on a Arakawa$\mathrm{C}$ grid. In the vertical, a terrain following hybrid sigma-type coordinate is used. The subgrid-scale physical processes described by parameterisation schemes are: radiation (RitterGeleyn, 1992, scheme), surface turbulent fluxes and vertical diffusion, soil processes, subgrid-scale clouds, moist convection (Tiedtke, 1989, mass-flux scheme), grid-scale clouds and precipitation. The microphysical scheme includes 5 hydrometeors, for which the prognostic equations are solved: cloud ice, cloud water, rain, snow, graupel. For a complete description of the model, the reader is referred to the COSMO web site (http://www.cosmo-model.org/, mirror site on http://cosmo-model.cscs.ch/).

ARPA-SIM has been using COSMO as the operational forecast model since 2001; COSMO is run twice a day (at 00:00 UTC and 12:00 UTC) for $72 \mathrm{~h}$ with a spatial horizontal resolution of $7 \mathrm{~km}$ and 40 layers in the vertical. The boundary conditions are supplied (one-way nesting) by the global model of the ECMWF (European Centre for Medium-range Weather Forecasts) every three hours. The initial condition is provided by a mesoscale data assimilation based on a nudging technique. The variables which are assimilated are: temperature, humidity and wind.

The model is also operational twice a day at $2.8 \mathrm{~km}$, with 45 vertical layers, nested (one-way) on the $7 \mathrm{~km}$ runs starting at 00:00 and 12:00 UTC. The forecast range is $48 \mathrm{~h}$.

For this work, the model (version 3.9) has been run in a slightly different configuration, since only 35 vertical layers have been used for both the $7 \mathrm{~km}$ and $2.8 \mathrm{~km}$ runs. Graupel was not available as a prognostic variable in model version 3.9. Initial and boundary conditions are provided by ECMWF analyses or forecasts for all the models, testing different configurations (Table 1). The model integration domains are shown in Fig. 5a.

In the COSMO hind +obs 7 experiment (control) the model is driven by ECMWF analyses every $6 \mathrm{~h}$ and observations are assimilated with the nudging technique throughout the whole running period $(60 \mathrm{~h}$, referred to as continuous assimilation in Table 1), while in the COSMO hind experiment no assimilation is performed. In the COSMO $f_{c} 7$ experiment, the initial condition is provided by a mesoscale data assimilation 
(a)



(b)

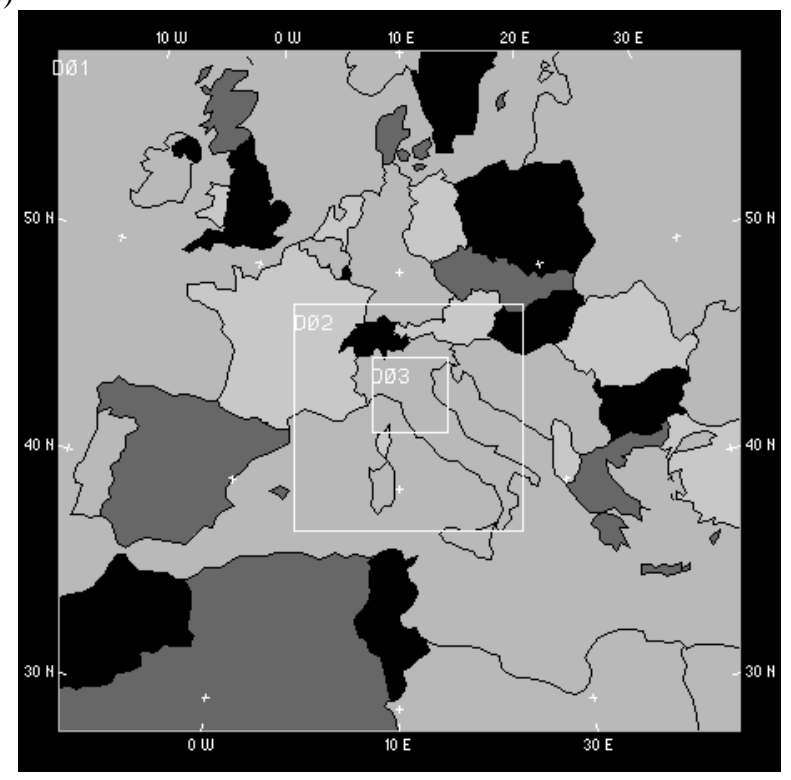

Fig. 5. Configuration of the domains used for: (a) the COSMO simulations with horizontal resolutions of 7 (larger domain) and 2.8 (smallest domain) $\mathrm{km}$ and (b) for the MM5 simulations with horizontal resolutions of $22.5,7.5$ and $2.5 \mathrm{~km}$ respectively. The Reno river basin is located between $44^{\circ}-44.5^{\circ} \mathrm{N}$ and $10.8^{\circ}-11.4^{\circ}$.

with the nudging technique over the preceding $12 \mathrm{~h}$ (referred to as COSMO analysis in Table 1), while the boundary conditions are provided every $3 \mathrm{~h}$ by the ECMWF operational model forecasts. In the latter case, therefore, a real time forecast is simulated. In the $2.8 \mathrm{~km}$ runs an explicit representation of the deep convection is allowed by switching off the Tiedtke convection scheme. The simulations are $72 \mathrm{~h}$ long.
Table 2. Performance of the rain-gauge driven runoff simulations for the 7-10 November 2003 episode and for the HEC-HMS and TOPKAPI hydrological models in terms of NSE efficiency criterion, $\% \mathrm{EV}$ and $\% \mathrm{EP}$ at Casalecchio flow-gauge.

\begin{tabular}{lccc}
\hline MODEL & NSE & \% EV & \% EP \\
\hline HMS & 0.86 & 13.2 & 24.9 \\
TOPKAPI & 0.77 & 34.7 & 21.2 \\
\hline
\end{tabular}

\subsection{MM5 model}

MM5 is a high-resolution short-range weather forecast model developed by the Pennsylvania State University (PSU) and the National Center for Atmospheric Research (NCAR) (Dudhia, 1993; Grell et al., 1995). Simulations are designed using 24 vertical $\sigma$-levels, with higher density near the surface to better resolve near-ground processes, and three spatial domains with $151 \times 151$ grid points centered in northwestern Italy (Fig. 5b). Their respective horizontal resolutions are $22.5,7.5$ and $2.5 \mathrm{~km}$. The interaction between the domains follows a two-way nesting strategy (Zhang and Fritsch, 1986). The second and third domains are used to supply the high-resolution rainfall fields to drive the hydrologic simulations depending on the runoff experiment. With the $2.5 \mathrm{~km}$ resolution driving data it is possible to test whether the enhanced representation of local topographic forcings leads to an improvement of the simulated precipitation fields.

To parameterise moist convection effects in the meteorological simulations, the modified Kain-Fritsch scheme (Kain and Fritsch, 1993) is used for the first and second domains. In the third domain, the convection is explicitly resolved owing to the very high-resolution. Moist microphysics is represented with prediction equations for cloud and rain water fields, cloud ice and snow allowing for slow melting of snow, supercooled water, graupel and ice number concentration (Reisner et al., 1998). The planetary boundary layer physics is formulated using a modified version of the Hong and Pan scheme (Hong and Pan, 1996). Surface temperature over land is calculated using a force-restore slab model (Blackadar, 1979; Zhang and Anthes, 1982) and over sea it remains constant during the simulations. Finally, long and short wave radiative processes are formulated using the RRTM scheme (Mlawer et al., 1997).

To initialize the model and to provide the boundary conditions, ECMWF (European Centre for Medium-range Weather Forecasts) analyses and forecasts are used depending on the experiment (Table 1). These fields are provided at a spatial resolution of $0.3^{\circ}$ and the update frequency for the boundary conditions is $6 \mathrm{~h}$. The tendencies along the boundaries of the coarse domain model, specified by differences of the fields between the $6 \mathrm{~h}$ apart data, are applied using a Newtonian relaxation approach (Grell et al., 1995). For the MM5 
Table 3. Contingency table of possible events for a selected threshold.

\begin{tabular}{llll}
\hline & \multicolumn{3}{c}{ Observed precipitation } \\
& Yes & No \\
\hline \multirow{2}{*}{ Forecasted precipitation } & Yes & $\mathrm{a}$ & $\mathrm{b}$ \\
\cline { 2 - 4 } & $\mathrm{No}$ & $\mathrm{c}$ & $\mathrm{d}$
\end{tabular}

hind $+o b s$ at 7.5 (control) and $2.5 \mathrm{~km}$ experiments, the first guess fields - interpolated from the ECMWF analyses on the MM5 model grid - are improved using surface and upper-air observations with a successive-correction objective analysis technique (Benjamin and Seaman, 1985). The whole set of MM5 simulations comprise a $48 \mathrm{~h}$ simulation period starting at 12:00 UTC on 7 November 2003.

\section{Results and discussion}

\subsection{Runoff simulations driven by rain-gauge data}

The stream-flow simulations are first driven by precipitation observations to be aware of the performance of both rainfall-runoff models. These rain-gauge driven flows will be used, instead of the observed discharge, for the comparison with the results derived from the meteorological models (Sect. 5.2). In such a way, the systematic error of the hydrological models will not affect the comparison. The skill of the resulting runoff simulations is expressed in terms of the Nash-Sutcliffe efficiency criterion (NSE; Nash and Sutcliffe, 1970). The performance of the runoff simulations is also checked by means of the relative error of total volume at Casalecchio Chiusa flow-gauge, expressed as percentage $(\% \mathrm{EV})$. Therefore, $\% \mathrm{EV}>0$ and $\% \mathrm{EV}<0$ would indicate an over and underestimation of the volume by the model, respectively. In addition, the relative error in percentage to the peak discharge has also been calculated (\% EP).

The observed hydrograph depicted a maximum discharge of $757.6 \mathrm{~m}^{3} \mathrm{~s}^{-1}$ on 21:00 UTC 8 November 2003 (Fig. 6). Rain-gauge driven runoff simulations show a similar performance in terms of peak runoff for both models, with a noticeable overestimation of $160.4 \mathrm{~m}^{3} \mathrm{~s}^{-1}$ and $188.4 \mathrm{~m}^{3} \mathrm{~s}^{-1}$ for TOPKAPI and HEC-HMS, respectively. This represents an overestimation of the observed peak flow slightly above of the $20 \%$ for TOPKAPI and very close to $25 \%$ for HEC-HMS, respectively. Otherwise, HEC-HMS reproduces the volume and the time base of the observed hydrograph more accurately than TOPKAPI. Therefore, NSE and \% EV result in a better performance for the former than the latter model (Table 2 and Fig. 6). The time to peak is identical for both models and it is simulated on 22:00 UTC 8 November 2003 with a delay of only $1 \mathrm{~h}$.

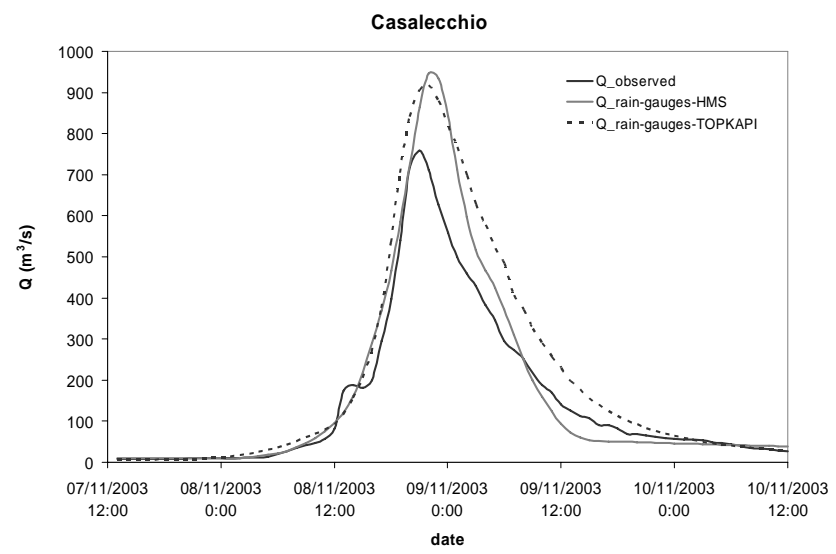

Fig. 6. Rain-gauge driven runoff simulations provided by HECHMS and TOPKAPI runoff models versus the observed discharge.

The overestimation of the runoff volumes and the peak discharges for both models can be ascribed to several factors. First, an inaccurate reproduction of the infiltration processes - that might lead to consider the initial soil moisture content slightly superior to the existent - can produce an overestimation of precipitation available for runoff during the event. Second, the presence of a small hydroelectric reservoir located in the upper catchment - which has not been modeled can also affect the modeled basin's response, since its impact on the flow regime and the runoff volume cannot be negligible.

On the other hand, both hydrological models fit the dynamical routing and the rising limb of the observed hydrograph quite well, in spite of not reproducing the first bump of runoff observed on 12:00 UTC 8 November 2003. This bump is due to a short intense raining period comprised within the forecast time steps 18 th and 21 st (Fig. 10), which especially affected the left side of the upper basin. Therefore, this failure could be ascribed to an inaccurate reproduction of the observed rainfall field over the area located in the left side of the upper basin, upstream to the Vergato river section (Fig. 4). The scarce presence of rain-gauges in this zone could have affected the accuracy of the rainfall inputs, leading to a slight and localised underestimation of the precipitation amounts.

It is also worth to remark the more smoothed recession limb obtained for the TOPKAPI rain-gauge driven simulation, although both models do not reproduce in an accurate way this feature. This result may be ascribed to several facts, such as: first, TOPKAPI reproduces the dynamics of the overall soil filling and depletion mechanisms and the flood routing in a more unrealistic way (particularly, underestimating the soil depletion mechanism) than HEC-HMS for the current case study, and second; the impact of the lack of modelling of the reservoir in the models' structure and its hydrograph diffusion effect in the flood wave can have a remarkable role in the aforementioned inaccuracies. Unfortunately, the technical characteristics and the release data for this reservoir are not available. 
(a)
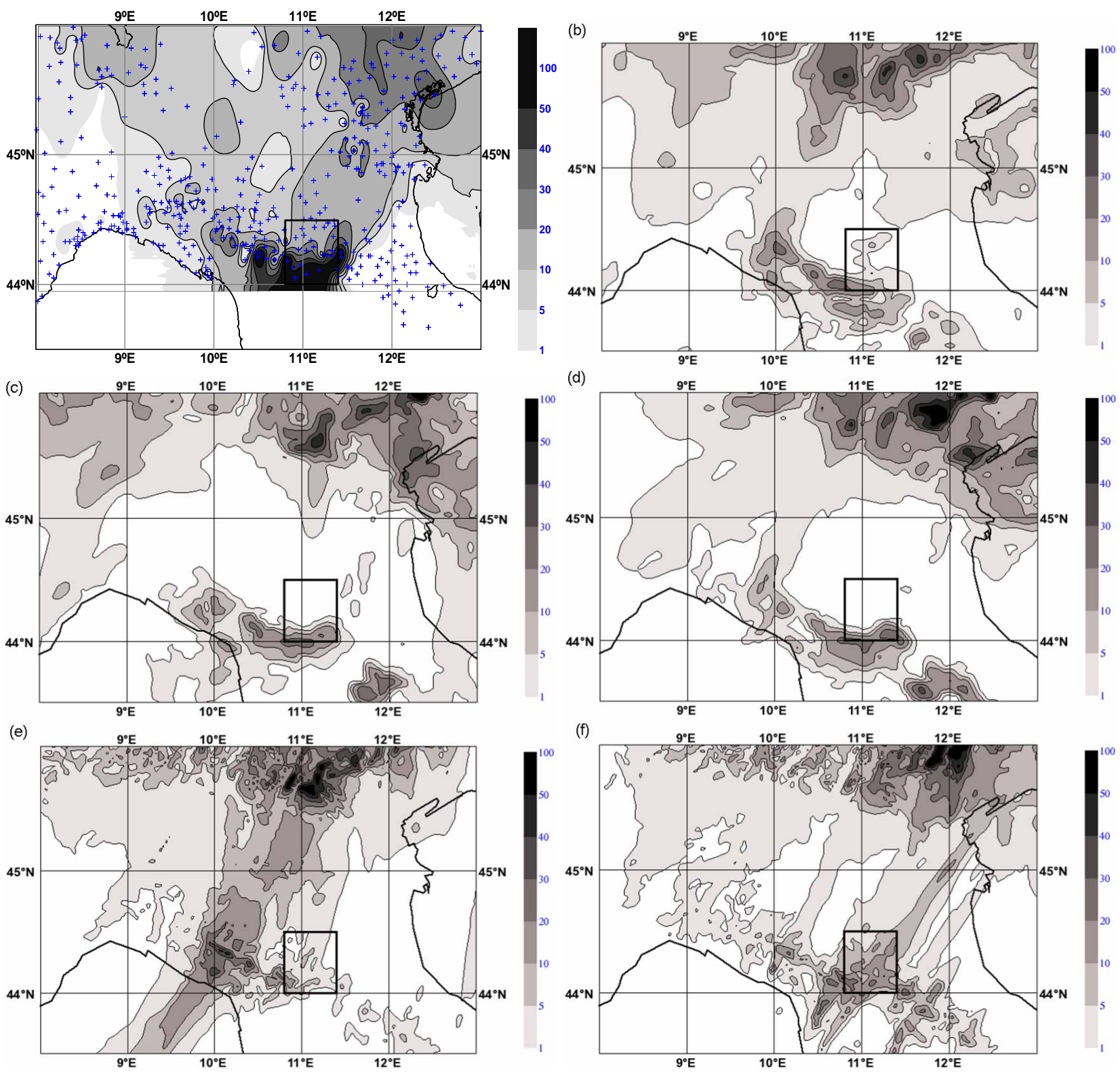

Fig. 7. Observed (a) and forecasted precipitation accumulated over $6 \mathrm{~h}$ (on 12:00-18:00 UTC 8 November 2003) provided by the following COSMO runs: (b) control (COSMO hind+obs 7), (c) COSMO hind 7, (d) COSMO fc 7, (e) COSMO hind+obs 2.8, (f) COSMO fc 2.8. Rainfall is shown in $\mathrm{mm}$ according to the scale. In Fig. 7a the blue crosses denote the rain-gauges, and the kriged observed precipitation has been blanked in the zones without rain-gauges in order to avoid artificial rainfall distributions.

Despite the abovementioned shortcomings, the reproduction of the flood event provided by both rain-gauge driven hydrological models simulations can be considered accurate, especially from the point of view of stakeholders (i.e. end users such as representatives from civil protection authorities for the aims of civil protection), since the timing and the order of magnitude of the event are well simulated.

\subsection{Runoff simulations driven by COSMO and MM5 ex- periments}

The COSMO and MM5 meteorological simulations have been evaluated at a scale larger than the basin by comparing the spatial observed and simulated rainfall accumulations over northern Italy in the 6-h period of maximum precipitation (from 12:00 to 18:00 UTC on 8 November 2003; Fig. 7a). Therefore, the analysis of the cumulative rainfall 
fields for this time window provides valuable information of the models' skill to simulate the more intense rainfall period. At this aim, a set of non-parametric statistical scores has been calculated through a point validation methodology. These scores are computed by using a $2 \times 2$ contingency table which summarizes in a categorical way the possible combinations of forecasted and observed events above and below a given rainfall threshold (Table 3). Then, Threat Score (TS), Bias Score (BIAS) and False Alarm Ratio (FAR) have been computed according to the following expressions (Jolliffe and Stephenson, 2003; Wilks, 2006):

$$
\begin{aligned}
& \mathrm{TS}=a /(a+b+c) \\
& \mathrm{BIAS}=(a+b) /(a+c) \\
& \mathrm{FAR}=b /(a+b)
\end{aligned}
$$

Briefly, the threat score indicates the correct proportion for the rainfall threshold being forecasted when it has been removed the correct no forecasts. A perfect forecast has TS $=1$. The bias score is the ratio of the number of positive forecasts to the number of positive observations. Unbiased forecasts exhibit BIAS=1. Finally, the false alarm ratio is the proportion of positive forecast events that fail to materialize. A perfect forecast has FAR $=0$. To interpolate the spatial distributions from the models' grid-points into the 579 rain-gauge point locations available over the domain, it has been used the bilinear interpolation method for each experiment. The set of thresholds includes values up to $50 \mathrm{~mm} / 6 \mathrm{~h}$ due to the high intensity of the observed rainfall amounts. It is worth to note that it has not been possible for some experiments to compute statistical scores at the largest thresholds, since the forecasts never exceeded these thresholds.

To quantify the skill of the precipitation fields provided by both COSMO and MM5 simulations at catchment scale, the area-averaged spatial and temporal distributions of these patterns are compared against the observed rainfall distribution over the Reno river basin by using two continuous statistical indices: the NSE and the mean absolute error (MAE). At this aim, the 13 subbasins segmentation of the catchment - carried out to implement the HEC-HMS runoff model in its semi-distributed configuration - has been used to evaluate the spatial distributions. Each individual subbasin has been used as an areal accumulation unit for the rainfall amounts over a $48 \mathrm{~h}$ time window, starting at 13:00 UTC on 7 November 2003. Thus, the results based on these cumulative rainfall fields provide information of the general performance of the models to simulate the whole event. The temporal distributions are computed by using hourly rainfall amounts over the whole basin and during the same $48 \mathrm{~h}$ time period. The hourly discretizations are found suitable in order to evaluate the ability of the mesoscale models of providing enough intense simulated rainfall fields, owing to the short times of concentration of the basin when it is affected by intense rainfall.
Table 4. NSE efficiency criterion and MAE (in $\mathrm{mm}$ ) of the spatial area-averaged rainfall distributions yielded by the set of mesoscale numerical simulations.

\begin{tabular}{lrrllr}
\hline experiment & NSE & MAE & experiment & NSE & MAE \\
\hline COSMO $f c$ 2.8 & 0.76 & 1.4 & MM5 fc 2.5 & -1.15 & 4.5 \\
COSMO fc 7 & -1.33 & 4.5 & MM5 fc 7.5 & -1.21 & 4.5 \\
COSMO hind 2.8 & -1.52 & 4.7 & MM5 hind 2.5 & -0.83 & 4.1 \\
COSMO hind 7 & -1.53 & 4.7 & MM5 hind 7.5 & -0.90 & 4.2 \\
COSMO control & -0.71 & 3.7 & MM5 control & -1.00 & 4.3 \\
& & & MM5 hind + obs 2.5 & -0.77 & 4.0 \\
\hline
\end{tabular}

\subsubsection{COSMO and MM5 control runs}

Six hourly accumulated precipitations provided by both COSMO and MM5 control simulations over northern Italy are analysed. The COSMO simulation reproduces quite well the precipitation occurred over the north-eastern Alps, even if the structure is spatially shifted (Fig. 7b), whereas the MM5 experiment shows a greater spread in simulating the precipitation field over the Alps, together with a slight overforecasting of the rainfall amounts (Fig. 8a). Both models do not forecast correctly the rainfall amounts observed within the Reno river basin, but capture the precipitation pattern over the western part of the Apennines. Therefore, the rainfall amounts inside the catchment are underestimated.

COSMO and MM5 control simulations show the highest TS value at small thresholds, with TS rapidly decreasing for higher thresholds (Fig. 9a and b). For medium and high thresholds, the MM5 control is better than COSMO in terms of TS. Both experiments underforecast the precipitation amounts over the whole domain (Fig. 9c and d), but the MM5 simulation presents a better performance with respect to COSMO, the MM5 BS being generally closer to 1. Regarding the FAR (Fig. 9e and f), both control experiments display a small proportion of incorrect forecasts for the lowest thresholds, but the false alarms increase rapidly for moderate and intense rainfall. At low- and mid-thresholds, the COSMO run is more accurate than the MM5 simulation. It seems that the greater rainfall amounts simulated by the MM5 experiment produce more hits but also more false alarms.

It is worth to note that both models are driven by the same initial and boundary conditions and with an assimilation of observational data. Therefore, the aforementioned differences can be ascribed to the different model formulations and, possibly, to the different physical parameterizations. Maybe the convection scheme of the MM5 model is responsible for the enhancement of the rainfall amounts within this complex orographic area. The higher vertical resolution of the COSMO model does not seem to be beneficial for this case.

Tables 4 and 5 depict the continuous skill scores for the area-averaged spatial and temporal rainfall distributions for both control runs over the catchment. Both the COSMO 
(a)

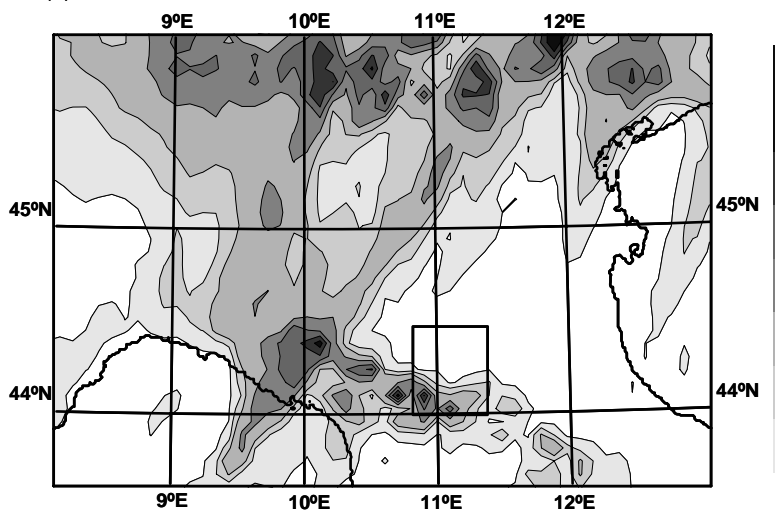

(c)

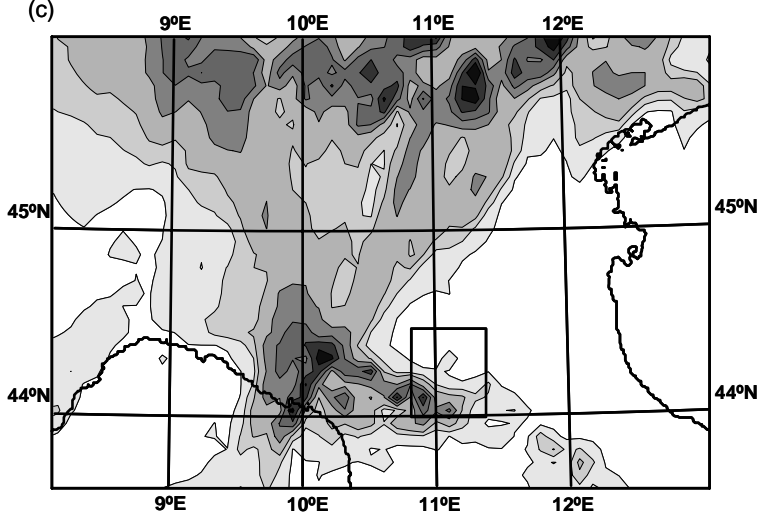

(e)

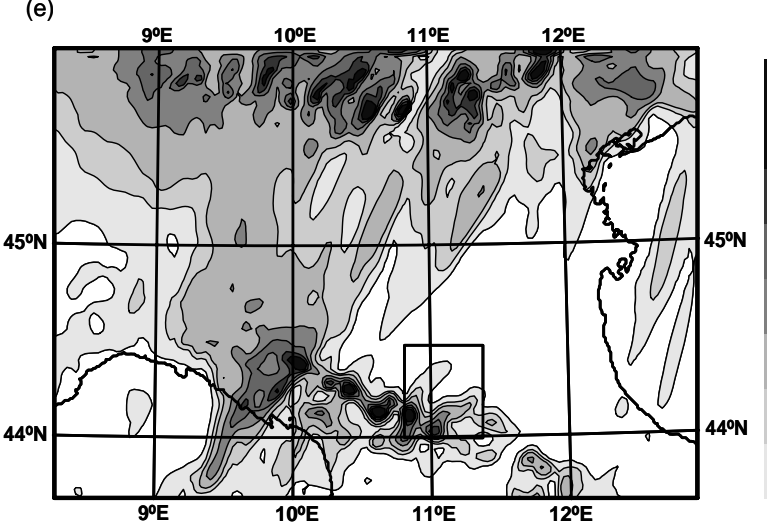

(b)



(d)

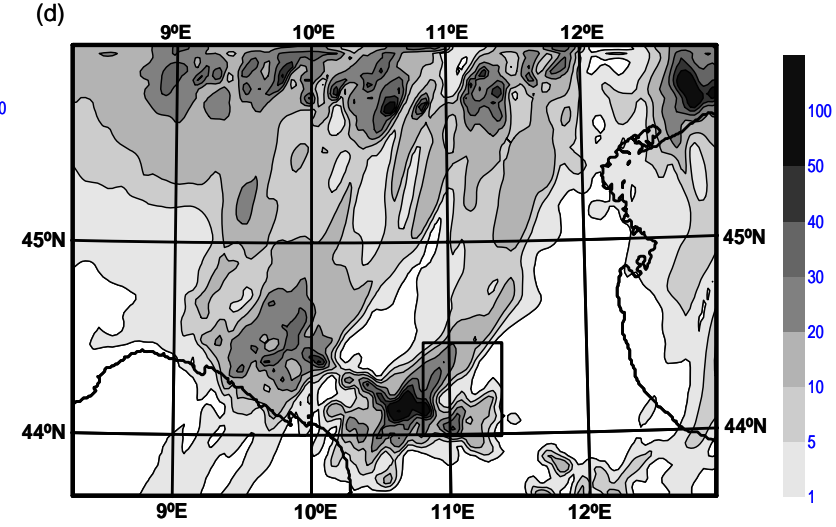

(f)



Fig. 8. Forecasted precipitation accumulated over $6 \mathrm{~h}$ (on 12-18 UTC 8 November 2003) provided by the following MM5 runs: (a) control (MM5 hind+obs 7.5), (b) MM5 hind 7.5, (c) MM5 fc 7.5, (d) MM5 hind+obs 2.5, (e) MM5 hind 2.5 and (f) MM5 $f c 2.5$. Rainfall is shown in $\mathrm{mm}$ according to the scale.

and MM5 simulations show a low forecasting skill at small scales. The inaccuracies in correctly forecasting the timing and rainfall amount over the upper Reno river basin are depicted in Figs. 10 and 11. In particular, the experiments miss the highest precipitation amounts observed around the 25th forecast hour. Therefore, the severe underestimation of the maximum precipitation amounts and the wrong timing are propagated to the subsequent driven runoff hydrographs (Tables 6 and 7), which exhibit a negative relative error in total volume. The hydrological runs (Figs. 12 and 13) simulate a discharge value exceeding only the warning threshold (i.e. $80 \mathrm{~m}^{3} \mathrm{~s}^{-1}$ ), but not the pre-alarm level (i.e. $630 \mathrm{~m}^{3} \mathrm{~s}^{-1}$ ): COSMO-TOPKAPI and COSMO-HEC driven experiments show a maximum peak discharge slightly superior to $275 \mathrm{~m}^{3} \mathrm{~s}^{-1}$ (Fig. 12a and b) and MM5-TOPKAPI and MM5-HEC driven runoff experiments yield maximum discharges slightly below $200 \mathrm{~m}^{3} \mathrm{~s}^{-1}$ (Fig. 13a and b). 
(a)

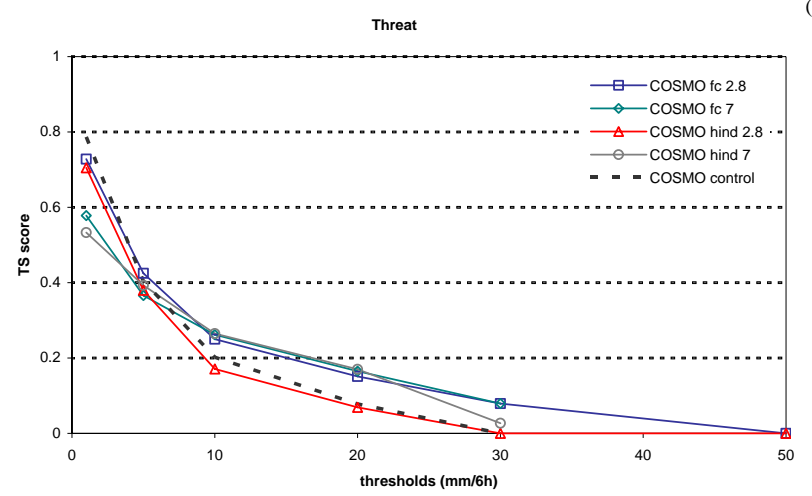

(d)

(c)

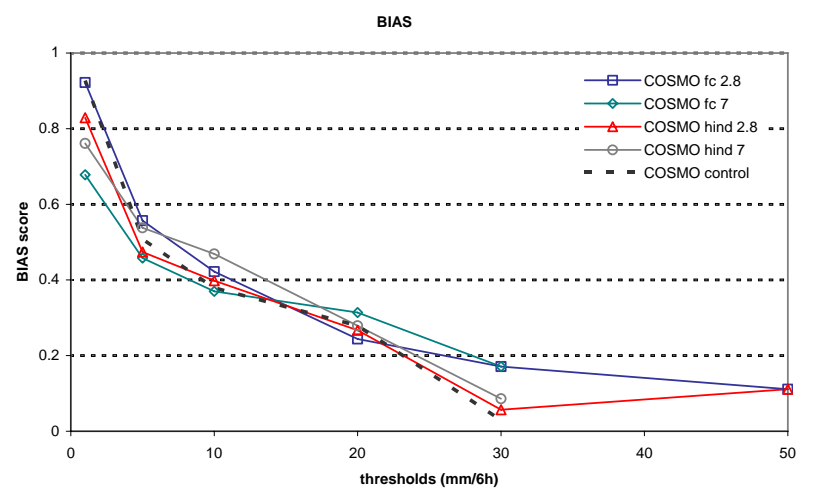

(f)

(e)

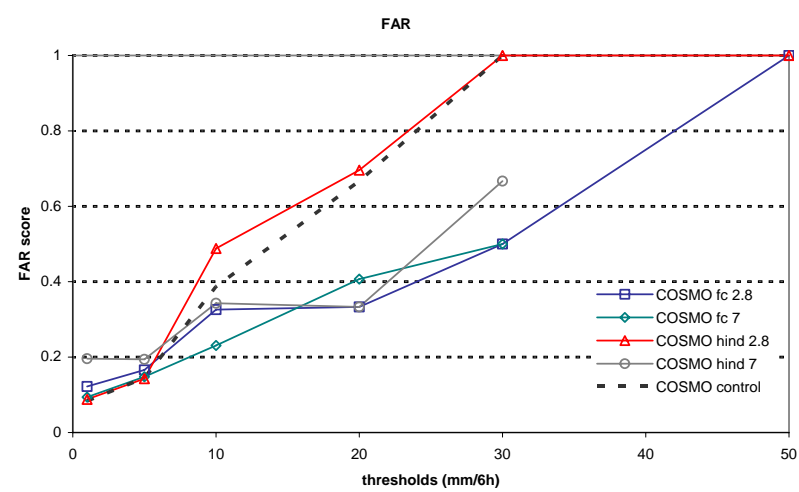

(b)
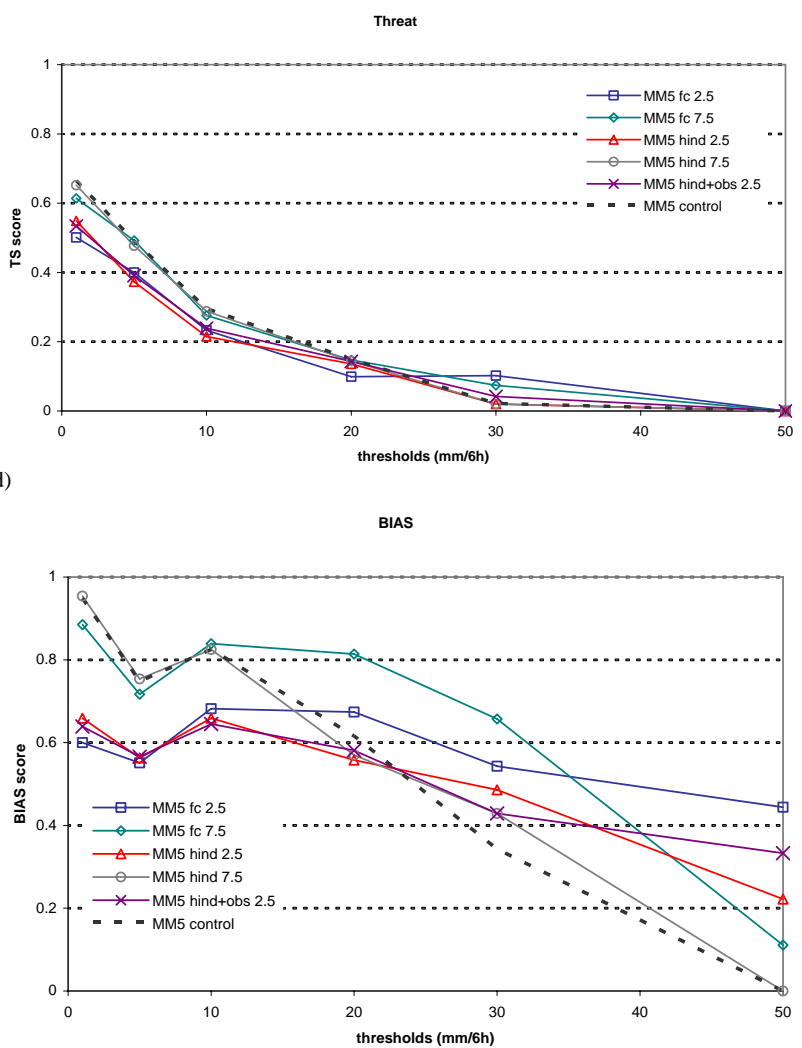

FAR



Fig. 9. TS, BIAS and FAR skill scores for different 6-h rainfall amount thresholds obtained by the COSMO and MM5 meteorological experiments.

\subsubsection{COSMO and MM5 experimental runs}

Following the motivation and methodology explained in the previous sections, a set of additional experiments is performed in order to produce the experimental meteorological model runs. Figures 7 and 8 show the observed and the simulated rainfall accumulations for the remaining COSMO and MM5 experiments over the 6-h period of maximum precipitation.

\section{(a) The COSMO based experiments}

All the COSMO runs reproduce the observed rainfall structure over the Apennines but underestimate the amounts, especially on the lee side over the Reno river basin (Fig. 7cf). The tendency to overestimate the rainfall in upwind areas in presence of a mountain range, with a related drying effect in the downwind regions, in case of intense precipitation forecast, has already been recognised as a typical feature of 



Fig. 10. (a) Observed and forecasted hourly area-averaged amounts and (b) cumulative hourly area-averaged amounts over the upper Reno river basin provided by the different configurations of COSMO model are displayed from 13:00 UTC 7 November 2003 until 00:00 UTC 09 November 2003.

the COSMO model (Elementi et al., 2005). This drawback heavily influences the reliability of the meteo-hydrological forecasting chain implemented for the concerned watershed, resulting in an underestimation of the forecast streamflow (Diomede et. al, 2008). In fact, being located on the northeastern side of the Apennine barrier, the Reno river basin clearly suffers from such a problem when the flow is from the south-west quadrant.

On the contrary, the precipitation occurred over the Alps is forecasted quite well in terms of rainfall amounts and their spatial distribution (Fig. 7c-f). In general, high-resolution experiments produce highest amounts of rainfall for this period; the best forecast is provided by the COSMO $f_{c} 2.8$ run (Fig. 7f). This simulation reproduces the whole rainfall structure quite well within the Reno river basin, but only forecasts moderate amounts of rain.

With regard to the Threat Score (Fig. 9a), COSMO highresolution experiments show the highest value at the smallest threshold. At the higher thresholds, no benefits are obtained by the high-resolution runs: COSMO hind 2.8 has the lower score, while COSMO $f_{c} 2.8$ has a similar behaviour to the $7 \mathrm{~km}$ runs. The underforecasting of the precipitation amounts over northern Italy, expressed by the BS (Fig. 9c), remains uncorrected, since no significant differences can be found
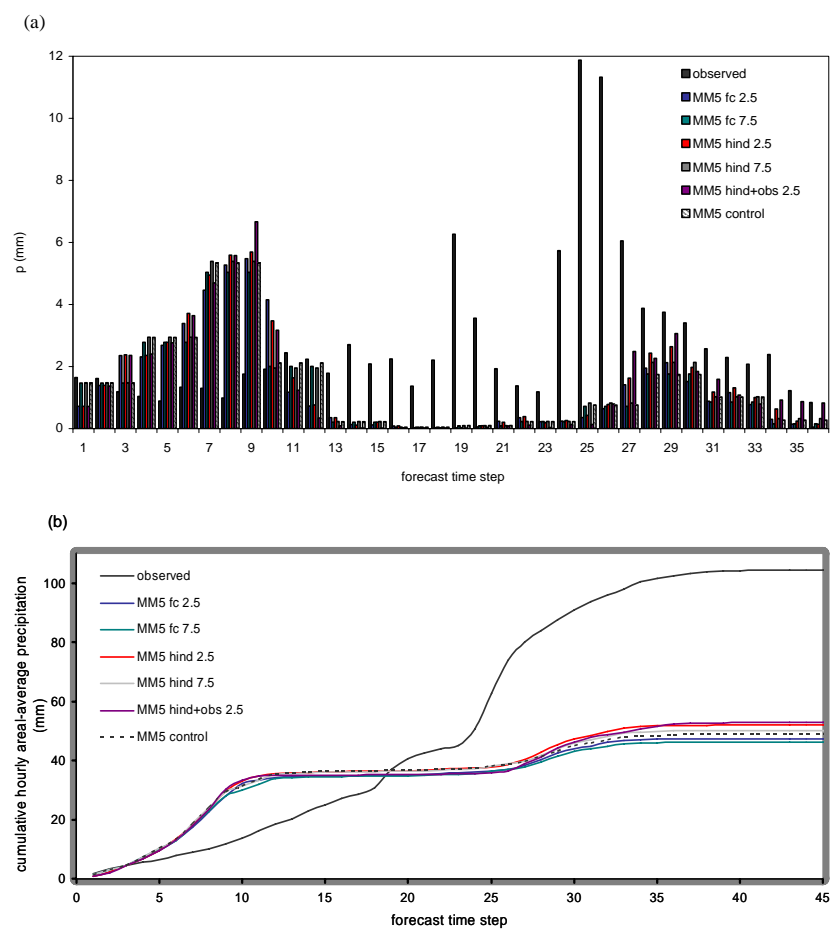

Fig. 11. (a) Observed and forecasted hourly area-averaged amounts and (b) cumulative hourly area-averaged amounts over the upper Reno river basin provided by the different configurations of MM5 model are displayed from 13:00 UTC 7 November 2003 until 00:00 UTC 09 November 2003.

Table 5. NSE efficiency criterion and MAE (in $\mathrm{mm}$ ) of the temporal area-averaged rainfall distributions yielded by the set of mesoscale numerical simulations.

\begin{tabular}{|c|c|c|c|c|c|}
\hline experiment & NSE & MAE & experiment & NSE & MAE \\
\hline COSMO fc 2.8 & -0.11 & 1.6 & $M M 5 f_{c} 2.5$ & -0.58 & 2.0 \\
\hline $\operatorname{COSMO} f_{c} 7$ & -0.30 & 1.7 & $M M 5 f c 7.5$ & -0.53 & 1.9 \\
\hline COSMO hind 2.8 & -0.80 & 2.1 & MM5 hind 2.5 & -0.55 & 1.9 \\
\hline COSMO hind 7 & -0.92 & 2.3 & MM5 hind 7.5 & -0.52 & 1.9 \\
\hline \multirow[t]{2}{*}{ COSMO control } & -0.46 & 1.7 & MM5 control & -0.54 & 1.9 \\
\hline & & & MM5 hind+obs 2.5 & -0.58 & 1.9 \\
\hline
\end{tabular}

among the different runs. The False Alarm Ratio is small at the lowest thresholds for all the experiments (Fig. 9e). At increasing thresholds, COSMO hind 2.8 has the worst performance, while $\operatorname{COSMO} f_{c} 2.8$ has a similar behaviour to the $7 \mathrm{~km}$ runs.

At the catchment scale, all the COSMO experiments miss the high precipitation amounts observed around the 25th forecast hour (Fig. 10a). However, the COSMO fc 2.8 experiment provides an underestimation of only about $10 \%$ for the total areal amount (Fig. 10b), even if this forecast is characterised by a wrong temporal distribution. Tables 4 and 5 confirm that this experiment exhibits the best forecasting skill in terms of NSE and MAE scores among all the COSMO runs. 
Table 6. NSE efficiency criterion and percentage of error in volume for the COSMO driven stream-flow experiments performed by the two hydrological models.

\begin{tabular}{lrrrr}
\hline Experiment & \multicolumn{2}{c}{ TOPKAPI } & \multicolumn{2}{c}{ HEC-HMS } \\
\hline & NSE & $\% \mathrm{EV}$ & NSE & $\% \mathrm{EV}$ \\
\hline COSMO fc 2.8 & 0.58 & -21.9 & 0.51 & -21.4 \\
COSMO fc 7 & -0.13 & -74.4 & -0.10 & -71.0 \\
COSMO hind 2.8 & -0.40 & -77.9 & -0.19 & -72.6 \\
COSMO hind 7 & -0.41 & -75.5 & -0.23 & -70.2 \\
COSMO control & 0.15 & -65.6 & 0.05 & -63.8 \\
\hline
\end{tabular}

The aforementioned inaccuracies of the COSMO simulations are propagated to the subsequent set of driven runoff simulations. Figure 12 depicts that the amplitudes of the simulated peaks are considerable smaller than the rain-gauge driven maximum discharge, except for the COSMO fc 2.8 driven experiment. For this experiment, a suitable reproduction can be pointed out for both HEC-HMS and TOPKAPI runs in terms of the peak flows and runoff volumes, although the time to peak is not well fitted. These features are reflected in their statistical scores (Table 6), the COSMO fc 2.8 driven experiments having the smallest values of relative error in volume. Therefore, it is worth to note the usefulness of the COSMO fc 2.8 driven experiment for the aims of civil protection: the exceeding of the pre-alarm threshold is forecast correctly, and the delay in the time to peak is not crucial with respect to the forecasting lead time.

\section{(b) The MM5 based experiments}

The maximum cumulative values for the MM5 experiments, in terms of precipitation over northern Italy, range from 66 to $93 \mathrm{~mm} / 6 \mathrm{~h}$. However, the highest values - rather similar to the observations - do not lie inside the basin, but westwards of the catchment in the Apennine range. The precipitation amounts occurred over the eastern part of the Alps are also well simulated, even if all the runs forecast excessive quantities over the western and the central Alps (Fig. 8b-f).

Threat Score shows a better performance for the lowresolution simulations at small- and mid-thresholds (Fig. 9b). At the greater thresholds, higher TS is obtained by the highresolution experiments, owing to the forecasting of higher rainfall amounts. It is worth to note that low-resolution experiments presents very similar TS values: it appears that the simulated rainfall patterns are rather insensitive to the different initial and boundary conditions used to initialize the MM5 experiments, at least in terms of this index. This feature can be a consequence of dealing with such complex orographic area. In addition, it seems clear that once the lowresolution simulations misplace the correct locations of the precipitation, the high-resolution experiments do not correct these errors due to the two-way nesting strategy.
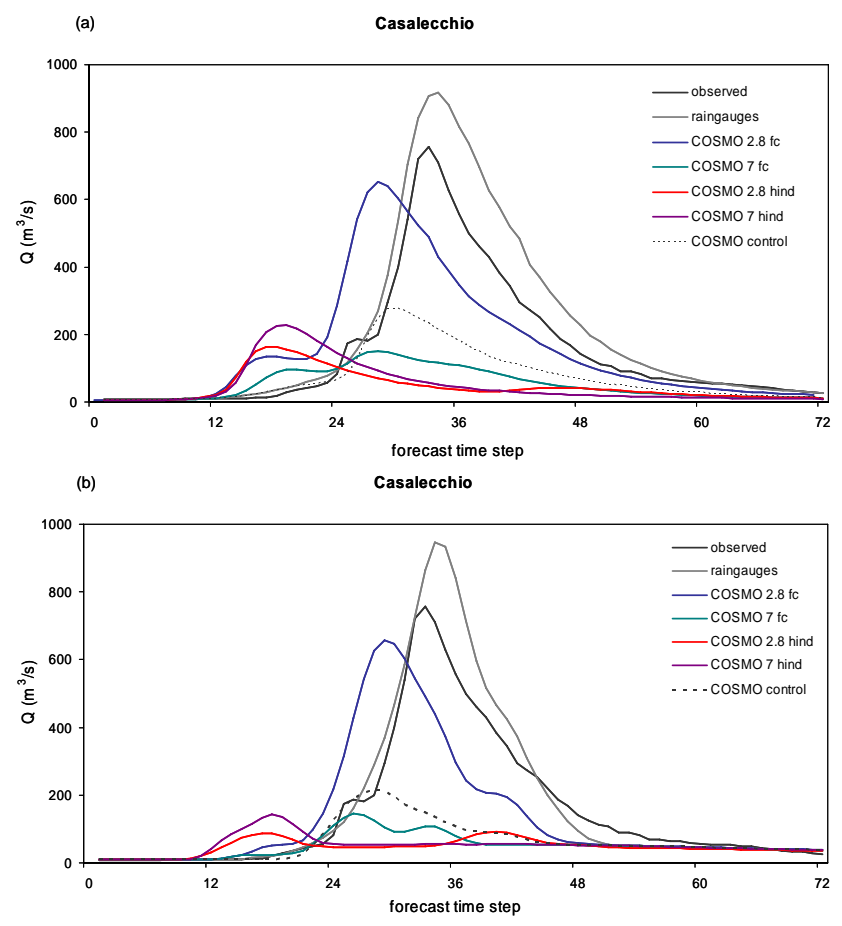

Fig. 12. (a) TOPKAPI and (b) HEC-HMS runoff simulations driven by the different configurations of COSMO, evaluated at Casalecchio outlet.

BIAS scores point out an underforecasting of the rainfall amounts over the whole domain for the MM5 runs, but this feature is more moderate than for the COSMO runs (Fig. 9d). Again, low-resolution predictions outperform the high-resolution forecasts at small thresholds. At medium thresholds, the MM5 fc 7.5 run has the best performance, followed by the MMS fc 2.5 run, while at the highest threshold the high-resolution runs perform better, since they provide higher rainfall amounts. FAR values indicate small differences among the low- and high-resolution experiments, and the expected continuous rise of the number of false alarms at increasing thresholds is found (Fig. 9f).

At the catchment scale, MM5 predictions distribute the maximum rainfall amounts for the upper Reno river basin over the first $12 \mathrm{~h}$ of simulation, completely missing the maximum quantities observed around the 25th forecast hour (Fig. 11a). In terms of the cumulative area-averaged precipitation amounts, the event is heavily underestimated by the simulations (about 50\%; Fig. 11b). This feature is reflected in Tables 4 and 5: a great homogeneity together with a small skill among all the MM5 simulations are found. These errors are propagated to the MM5 driven runoff simulations. In fact, small differences are found among the low- and highresolution driven discharge peak flows (Fig. 13) and discharge volumes (Table 7). Therefore, the flood event is neither simulated in an accurate way by TOPKAPI nor HECHMS runoff models. 

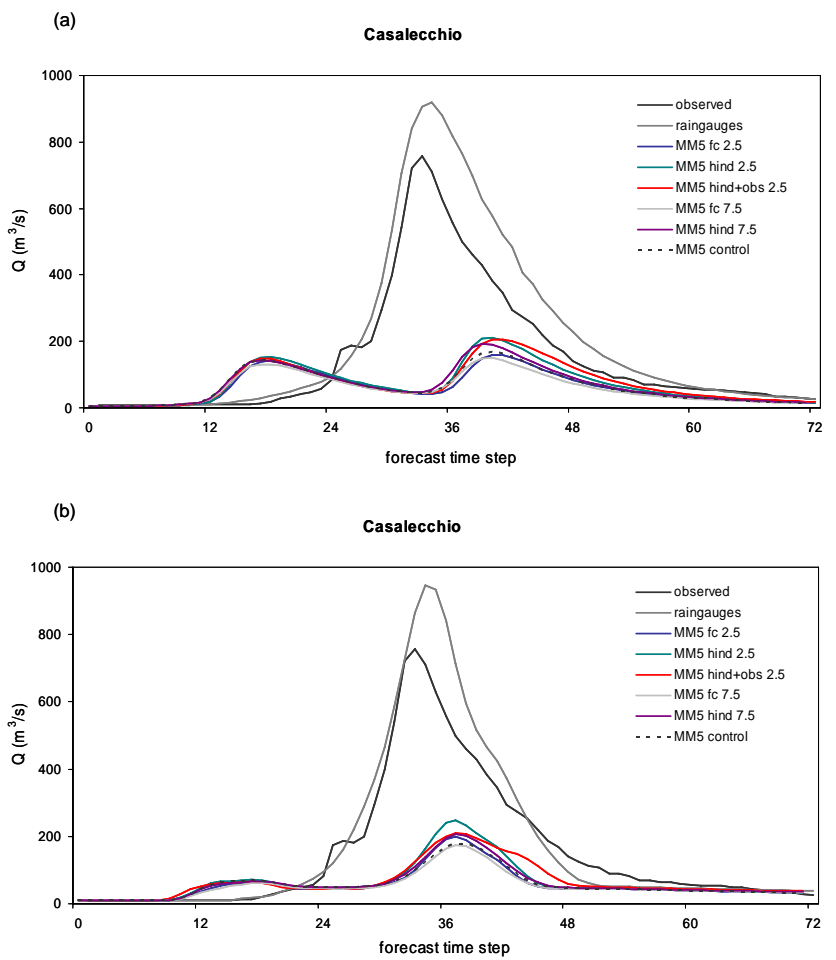

Fig. 13. (a) TOPKAPI and (b) HEC-HMS runoff simulations driven by the different configurations of MM5, evaluated at Casalecchio outlet.

\subsection{Further remarks}

The comparison among the low-resolution COSMO and MM5 experiments shows the impact of the different model formulation and physical parameterizations (i.e. cloud microphysics, moist convection, boundary layer) on the structure and amounts of the simulated rainfall fields for the investigated event over this complex orographic area. It is found that BIAS scores are closer to 1 for MM5 than for COSMO simulations almost for all the thresholds. The different schemes used for the parameterization of the deep convection in the two models can play a role in determining this result. In fact, this may be due to the fact that the modified Kain-Fritsch scheme of MM5 produces higher precipitation amounts on the domain - rather similar to the observations -, but too much scattered. On the contrary, the Tiedtke moist convection parameterization of COSMO drives to noticeable underestimations of the rainfall amounts, but more constrained to the correct locations.

With regard to the COSMO simulations, the use of different initial and boundary conditions results beneficial, since it appears that a part of the error of the control simulation comes from the inaccuracies found in the boundary conditions. On the contrary for the MM5 simulations, the use of different initial and boundary conditions does not contribute to an improvement of the simulated rainfall fields:
Table 7. NSE efficiency criterion and percentage of error in volume for the MM5 driven stream-flow experiments performed by the two hydrological models.

\begin{tabular}{lrrrr}
\hline Experiment & \multicolumn{2}{c}{ TOPKAPI } & \multicolumn{2}{c}{ HEC-HMS } \\
\hline & NSE & $\%$ EV & NSE & $\%$ EV \\
\hline MM5 $f c$ 2.5 & -0.21 & -70.2 & 0.01 & -67.9 \\
MM5 $f c 7.5$ & -0.22 & -71.6 & -0.03 & -69.6 \\
MM5 hind 2.5 & -0.12 & -64.7 & 0.10 & -62.8 \\
MM5 hind 7.5 & -0.15 & -66.8 & 0.04 & -65.4 \\
MM5 hind + obs 2.5 & -0.13 & -64.1 & 0.08 & -61.8 \\
MM5 control & -0.20 & -68.8 & 0 & -67.3 \\
\hline
\end{tabular}

low-resolution experiments resemble each other in terms of the forecast hits. Furthermore, the assimilation of mesoscale observations during the hindcast runs does not lead to a significant improvement for both models.

The increase of the horizontal resolution - which permits an explicit representation of deep convection - results in an enhancement of the simulated rainfall amounts for the event. One of the high-resolution COSMO simulations shows a significant improvement in the rainfall forecast over the basin, indicating that the explicit representation of the convection plays an important role, in association with more accurate boundary conditions. However, the high-resolution MM5 experiments do not provide an improvement on the location of the simulated rainfall patterns over the Reno river basin. This fact highlights the impact of the different nesting strategies: the set of COSMO simulations displays a larger spread when compared with the set of MM5 experiments, both in terms of the spatial distributions and of the cumulative hourly areaaveraged rainfall amounts throughout the forecasting period. The two-way nesting strategy results in small differences among the low- and high-resolution spatial rainfall patterns. Therefore, the wrong locations of the cores of maximum precipitations remain uncorrected.

It is important to emphasize the different responses of the two hydrological models when driven with the same rainfall forecast. The simulations provided by TOPKAPI show quite similar peak discharges in response to similar raining periods. Otherwise, the experiments provided by HEC-HMS are commonly characterised by a smaller increase of the streamflow in response to the first raining period, but higher values in response to the later ones. These differences can be mainly attributed to the different infiltration schemes adopted by the two models: TOPKAPI exploits the first hours of the QPFs to saturate the soil - following a dunnian mechanism -, whereas HEC-HMS directly exploits the initial rainfall amounts to calculate the runoff volumes after subtracting an initial abstraction. Then, with the SCS-CN method, once the initial infiltration threshold has been exceeded, the efficiency of the watershed in producing runoff increases while precipitation occurs. 
The impact of the different calibration procedures -carried out during different time windows- in the optimization of the initial configuration for both runoff models have not resulted in great discrepancies. TOPKAPI is a distributed and continuous run model, whereas HEC-HMS has been implemented in a semi-distributed and event-based configuration. In the former case, the longer is the calibration time, the more reliable are the simulated flows. In the latter case and for the aim of the present work, it has been chosen to perform the calibration process by only selecting a set of events with the greatest similarity to the event under study. Although this approach has demonstrated to be suitable for this case study, it must not be forgotten that within a flood forecasting framework, the use of long rainfall and runoff observed series leads to a great confidence interval for hydrological modeling. In addition, it avoids that the models only work well within a limited range of calibration events.

It is also worth to note that the hydrological models have been forced separately with observed and simulated rainfall fields obtained by two different applications of the kriging method. These methodologies can be considered to have a negligible influence on the subsequent simulated flows. In fact, the impact of the different schemes of the physical processes adopted by the runoff models plays a major role in determining the results. Equivalently, the uncertainties related to the kriging methods can be considered to have a minor role as compared to the uncertainties related to the quantitative precipitation forecasts provided by the NWP models. Furthermore, a sensitivity test to the choice of the variogram has been performed to confirm this hypothesis. It has been selected a linear, an exponential and a Gaussian variogram to spatially distribute the rain-gauges observations. The results (not shown) reveal that very weak differences among the observed patterns have been found.

\section{Conclusions}

This work has proposed a hydrometeorological model intercomparison in order to estimate the uncertainties associated with the hydrometeorological forecasting chain for an intense rainfall episode which affected northern Italy on 710 November 2003. The flood event which occurred over the upper Reno river basin, a medium size catchment in the Emilia-Romagna Region, has been investigated in detail. To fulfil this aim, the one-way coupled atmospherichydrological model simulations have been performed by using the COSMO and MM5 meteorological and the HECHMS and TOPKAPI hydrological models.

The meteorological runs have been carried out in a research or operational mode depending on the experiment. These simulations have been evaluated by a threefold approach. The first procedure uses a point validation methodology by means of categorical verification indices. This method allows to assess the performance of the simulated rainfall patterns at large scales. The second and third procedures examine the QPFs at catchment scale by using continuous verification scores, and by adopting the coupled atmospheric-hydrological models system as a validation tool. The aim of this study is to investigate which hydrological and meteorological modeling factors could help to enhance the hydrometeorological modeling of such hazardous events in the Western Mediterranean.

The meteorological simulations have shown deficiencies in the forecast of precipitation over the Reno river basin, in terms of timing, location and amount of the rainfall patterns at the catchment scale. These deficiencies have a major impact on the subsequent hydrological simulations. However, an enhancement of the horizontal meteorological model resolution has considerably improved the rainfall forecast for one of the experiments. This simulation has benefited also of forecast boundary conditions, which for this case have proved to be more accurate than the analysed ones, and of an initial condition obtained through a mesoscale data assimilation.

However, the remaining experiments have shown that the large-scale shift errors on the precipitation patterns can not be corrected by only enhancing the model resolution. In this case the improvement of initial and boundary conditions turns out to play an important role. Furthermore, the oneway nesting methodology adopted by COSMO has proved to introduce broader spread among the different simulations, allowing to obtain more different forecast scenarios, while high- and low-resolution MM5 simulations resemble each other, since a two-way nesting strategy is used.

Remarkable differences in the simulated precipitation amounts and their timing and localisation have been found depending on the model itself and in particular on the physical models' parameterizations.

The performance of both hydrological models has shown weak discrepancies, in spite of the differences between their parameterizations, structures and set-up. Concretely, no remarkable differences have been found for flood modeling purposes by using either a distributed and continuous or a semi-distributed and event-based configuration. This issue could be of importance for operational flood forecasting in case of intense, but not extreme, rainfall episode over the Reno river basin. In fact, the characteristics of the rainfall event (i.e. spatial-temporal distribution and intensity) may influence the simulated catchment's response, especially with respect to the modelled soil infiltration mechanism.

In addition, the present study has allowed to compare the performance of two hydrologic models, and to evaluate the impact of their different structures in the performance of the proposed flood forecasting chain and in assessing the different sources of uncertainties involved in the forecasting process. The use of two different models, which may be able to reproduce separately different parts of the hydrograph well, makes this intercomparison more valuable for the operational practice. 
The difficulties in the precise reproduction of the timing and locations of the rainfall amounts for this event still remain as a challenging issue. This could be addressed by improving the description of both the meteorological and hydrological components, as well as their coupling. For example, the implementation of an ensemble strategy would be desirable. This could be achieved by using the ECMWF Ensemble Prediction System to provide initial and boundary conditions or by using a broad multi-model and multianalyses system to drive the limited-area runs. Furthermore, it could be advisable the implementation of assimilation techniques connecting the one-way coupling among hydrological and meteorological models. Some examples of these techniques are different applications of statistical downscaling (e.g. Hewitson and Crane, 1992; von Storh and Zwiers, 1999; Wilks, 1999; Antolik, 2000; Clark and Hay, 2004) or disaggregation techniques (Deidda et al., 1999; Deidda, 2000; Ferraris et al., 2002), which will be the subject for future developments.

Acknowledgements. Michael Bruen, associated editor of the NHESS special issue on "Propagation of uncertainty in advanced meteo-hydrological forecast systems", and two anonymous reviewers are deeply acknowledge for their valuable comments which helped to improve the quality of this work. Víctor Homar from the Meteorology Group of the Balearic Islands University is also acknowledge for his assistance with the MM5 model. This study pertains to the activities of AMPHORE (Application des Méthodologies de Prévisions Hydrométéorologiques Orientées aux Risques Environnementaux), a European MEDOCC INTERREG III B project. This work has been also sponsored by CGL 200503918/CLI (PRECIOSO) Spanish project.

Edited by: M. Bruen

Reviewed by: two anonymous referees and Michael Bruen

\section{References}

Amengual, A., Romero, R., Gómez, M., Martín, A., and Alonso, S.: A hydrometeorological modeling study of a flash-flood event over Catalonia, Spain, J. Hydrometeor., 8, 282-303, 2007.

Anquetin, S., Yates, E., Ducrocq, V., and Coauthors: The 8 and 9 September 2002 flash flood event in France: a model intercomparison, Nat. Haz. Earth Sys. Sci., 5, 741-754, 2005.

Antolik, M. S.: An overview of the National Weather Service's centralized statistical quantitative precipitation forecast, J. Hydrol., 239, 306-337, 2000.

Atkinson, S., Woods, R. A., and Sivapalan, M.: Climate and landscape controls on water balance model complexity over changing time scales, Water Res. Research, 38(12), 50.1-50.17, 1314, doi: 10.1029/2002WR001487, 2002.

Atkinson, S., Sivapalan, M., Woods, R. A., and Viney, N. R.: Dominant physical controls of hourly streamflow predictions and an examination of the role of spatial variability: Mahurangi catchment, New Zealand, Adv. Water Res., 26(3), 219-235, 2003.

Bacchi, B., Buzzi, A., Grossi, G., and Ranzi, R.: Flood forecasting in a midsize catchment in the southern Alps: Recent experiences on the use of couple meteorological and hydrological model, Proceedings of the third EGS Plinius conference, Baja Sardinia, Consiglio Nazionale delle Ricerche, Roma, Italy, 201208, 2002.

Bacchi, B. and Ranzi, R.: Hydrological and meteorological aspects of floods in the Alps: an overview, Hydrol. Earth Sys. Sci., 7, 785-798, 2003.

Benjamin, S. G. and Seaman, N. L.: A simple scheme for improved objective analysis in curved flow, Mon. Weather Rev., 113, 1184 1198, 1985.

Benoit, R., Pellerin, P., Kouwen, N., Ritchie, H., Donaldson, N., Joe, P., and Soulis, E.: Toward the use of coupled atmospheric and hydrologic models at regional scale, Mon. Weather Rev., 128, 1681-1706, 2000.

Benoit, R., Kouwen, N., Yu, W., Chamberland, S., and Pellerin, P.: Hydrometeorological aspects of the Real-Time Ultrafinescale Forecast Support during the Special Observing Period of the MAP, Hydrol. Earth Sys. Sci., 7, 877-889, 2003.

Bhagarva, M. and Danard, M.: Application of optimum interpolation to the analysis of precipitation in complex terrain, J. Appl Meteor., 33, 508-518, 1994.

Blackadar, A. K.: High resolution models of the planetary boundary layer, Adv. Environ. Sci. Eng., 1, 50-85, 1979.

Butts, M. B.: Coupling of catchment modelling and meteorological information in flow forecasting, PIK Report no. 65, Proc. of European Conf. on advances in flood research, edited by: Bronsert, A., Bismuth, C., and Menzel, C., Potsdam-Institut für Klimafolgenforschung, 476-487, 2000.

Butts, M. B., Payne, J. T., Kristensen, M., and Madsen, H.: An evaluation of the impact of model structure on hydrological modelling uncertainty for streamflow simulation, J. Hydrol., 298, 242-266, 2004.

Chancibault, K., Anquetin, S., Ducrocq, V., and Saulnier, G.-M.: Hydrological evaluation of high-resolution precipitation forecast of the Gard flash-flood event (8-9 September 2002), Q. J. Roy. Meteor. Soc., 132, 1091-1117, 2006.

Chow, V. T., Maidment, D. R., and Mays, L. W.: Applied Hydrolology, McGraw-Hill, 572 pp., 1988.

Clark, M. P. and Hay, L. E.: Use of medium-range numerical weather prediction model output to produce forecasts of streamflow, J. Hydrometeorol., 5, 243-262, 2004.

Deidda, R., Benzi, R., and Siccardi, F.: Multifractal modelling of anomalous scaling laws in rainfall, Water Resour. Res., 35, 1853-1867, 1999.

Deidda, R.: Rainfall downscaling in a space-time multifractal framework, Water Resour. Res., 36, 1779-1794, 2000.

Diomede, T., Marsigli, C., Nerozzi, F., Papetti, P., and Paccagnella, T.: Coupling high resolution precipitation forecasts and discharge predictions to evaluate the impact of spatial uncertainty in NWP model output, Meteor. Atmos. Phys., (in press), 2008 .

Ducrocq, V., Lebeaupin, C., Thouvenin, T., and Anquetin, S.: Mesoscale modelling of a cooding storm, Application to the extreme flood of Gard, 5th EGS Plinius conference, Ajaccio, Corsica, France, 2003.

Dudhia, J.: A nonhydrostatic version of the Penn State/NCAR mesoscale model: Validation tests and simulation of an Atlantic cyclone and cold front, Mon. Weather Rev., 121, 1493-1513, 1993.

Elementi, M., Marsigli, C., and Paccagnella, T.: High resolution forecast of heavy precipitation with Lokal Modell: analysis of 
two case studies in the Alpine area, Nat. Hazard Earth Sys. Sci., 5, 593-602, 2005.

Farmer, D., Sivapalan, M., and Jothityangkoon, C.: Climate, soil and vegetation controls upon the variability of water balance in temperate and semi-arid landscapes: downward approach to hydrological prediction, Water Res. Research., 39(2), 1035, doi:10.1029/2001WR000328, 2003.

Ferraris, L., Rudari, R., and Siccardi, F.: The uncertainty in the prediction of flash floods in the Northern Mediterranean environment, J. Hydrometeorol., 3, 714-727, 2002.

Georgakakos, K. P., Seo, D.-J., Gupta, H., Schaake, J., and Butts, M. B.: Characterising streamflow simulation uncertainty through multimodel ensembles. J. Hydrol., 298(1-4), 222-241, 2004.

Gerlinger, K. and Demuth, N.: Operational flood forecasting for the Moselle river basin, PIK Report no. 65, Proc. of European Conf. on advances in flood research, edited by: Bronsert A., Bismuth, C., and Menzel, C., Potsdam-Institut für klimafolgenforschung, $562-573,2000$.

Grell, G. A., Dudhia, J., and Stauffer, D. R.: A description of the fifth-generation of the Penn State/NCAR mesoscale model (MM5), NCAR Tech. Note NCAR/TN-398+STR, Boulder, USA, 1995.

Hearman, A. J. and Hinz, C.: Sensitivity of point scale surface runoff predictions to rainfall resolution, Hydrol. Earth Sci., 11(2), 965-982, 2007.

Hewitson, B. C. and Crane, R. G.: Large-scale atmospheric controls on local precipitation in tropical Mexico, Geophys. Res. Lett., 19, 1835-1838, 1992.

Hong, S.-Y. and Pan, H.-L.: Nonlocal boundary layer vertical diffusion in a medium-range forecast model, Mon. Wea. Rev., 124, 2322-2339, 1996.

Jasper, K. and Kaufmann, P.: Coupled runoff simulations as validation tools for atmospheric modelsat the regional scale, Q. J. Roy. Meteor. Soc., 129, 673-692, 2003.

Jolliffe, I. T. and Stephenson, D. B.: Forecast verification, A practitioner's guide in atmospheric science, John Wiley and Sons Ltd., Chichester, West Sussex, England, 240 pp., 2003.

Kain, J. S. and Fritsch, J. M.: The role of the convective "trigger function" in numerical forecasts of mesoscale convective systems, Meteor. Atmos. Phys. Amer., 49, 93-106, 1992.

Kain, J. S. and Fritsch, J. M.: Convective parameterization for mesoscale models: The Kain-Fritsch scheme. The representation of cumulus in numerical models, Amer. Meteor. Soc., 24, 165-170, 1993.

Koren, V. I., Reed, S., Smith, M., Zhang, Z., and Seo, D.-J.: Hydrology Laboratory Research Modeling System (HL-RMS) of the National Weather Service, J. Hydrol., 291, 297-318, 2004.

Krajewski, W. F.: Cokriging radar-rainfall and rain gauge data, J. Geophys. Res., 92(D8), 9571-9580, 1987.

Kunstmann, H. and Stadler, C.: Operational high resolution meteorological and hydrological analysis as decision support system in integrated water resources management, in: IAHS Redbook "Integrated water resources management: Towards sustainable water utilization in the 21 st century", edited by: Grgens, A. et al., IAHS Redbook, 2004.

Linsley, R. K., Kohler, M. A., and Paulhus, J. L. H.: Hydrology for engineers, McGraw-Hill, New York, 3rd edition, 508 pp., 1982.

Liu, Z. and Todini, E.: Towards a comprehensive physically-based rainfall-runoff model, Hydrol. Earth Sci., 6, 859-881, 2002.
Mariani, S., Casaioli, M., Accadia, C. and Coauthors: A limited area model intercomparison on the "Monserrat-2000" flash-flood event using statistical and deterministic methods, Nat. Haz. Earth Sci., 5, 565-581, 2005.

Mazzetti, C. and Todini, E.: Deliverable 7.1 - Development and application of the block Kriging technique to rain-gauge data, Resulting from Work package 7, MUSIC Multi-sensor Precipitation calibration and flood forecasting, project supported by the European Commission under Contract No. EVK1-CT-2000-00058, (www.geomin.unibo.it/orgv/hydro/music/index2.htm), 2004.

Mlawer, E. J., Taubman, S. J., Brown, P. D., Iacono, M. J., and Clough, S. A.: Radiative transfer for inhomogeneous atmosphere: RRTM, a validate correlated-k model for the long wave, J. Geophys. Rev., 102(D14), 16 663-16682, 1997.

Nash, J. E. and Sutcliffe, J. V.: River flow forecasting through conceptual models, Part I: A discussion of principles, J. Hydrol., 10(3), 282-290, 1970.

Obled, C., Djerboua, A., Zin, I., and Garçon, R.: A simple probabilistic flood forecasting chain with focus on the use of QPF's, Proc. of the ESF LESC Exploration Workshop, Bologna, Italy, in: Hydrological risk recent advances in peak river flow modelling, prediction and real-time forecasting - assessment of the impacts of land-use and climate changes, edited by: Brath, A., Montanari, A., and Toth, E.,Editoriale Bios, Castrolibero, CS, Italy, 168-185, 2004.

Ranzi, R., Bacchi, B., Grossi, G., Buzzi, A., Malguzzi, P., Ratto, C., and Corazza M.: Previsioni di piena mediante un modello idrologico e un modello meteorologico ad area limitata: alcune esperienze applicative durante l'esperimento MAP-SOP. Atti del XXVII Convegno di Idraulica e Costruzioni Idrauliche, Genova, 12-15 settembre 2000, Vol. II, 385-393, 2000.

Ranzi, R., Bacchi, B., and Grossi, G.: Runoff measurements and hydrological modelling for the estimation of rainfall volumes in an Alpine Basin, Q. J. Roy. Meteor. Soc., 129, 653-672, 2003.

Refsgaard, J. C. and Knudsen, J.: Operational validation and intercomparison of different types of hydrological models, Water Res. Research, 32(7), 2189-2202, 1996.

Reisner, J., Rasmussen, R. J., and Bruintjes, R. T.: Explicit forecasting of supercooled liquid water in winter storms using the MM5 mesoscale model, Q. J. Roy. Meteor. Soc., 124B, 1071-1107, 1998.

Ritter, B. and Geleyn, J. F.: A comprehensive radiation scheme for numerical weather prediction models with potential applications in climate simulations, Mon. Weather Rev., 120, 303-325, 1992.

Roeckner, E., Bengtsson, L., Feichter, J., and Rodhe, H.: Transient climate change simulations with a coupled atmosphere-ocean GCM including the tropospheric sulphur cycle, Max Planck Institut für Meteorologie, Rep., 266, Hamburg, Germany, 1998.

Seo, D. J.: Real-time estimation of rainfall fields using radar rainfall and rain gage data, J. Hydrol., 208, 37-52, 1998.

Stensrud, D. J. and Fritsch, J. M.: Mesoscale convective systems in weakly forced large-scale environments. Part II: Generation of a mesoscale initial condition, Mon. Weather Rev., 122, 20682083, 1994a.

Stensrud, D. J. and Fritsch, J. M.: Mesoscale convective systems in weakly forced large-scale environments, Part III: Numerical simulations and implications for operational forecasting, Mon. Weather Rev., 122, 2084-2104, 1994b. 
Steppeler, J., Doms, G., Schättler, U., Bitzer, H. W., Gassmann, A., Damrath, U., Gregoric, G.: Meso-gamma scale forecasts using the non-hydrostatic model LM, Meteorol. Atmos. Phys., 82, 7596, 2003.

Tiedtke, M.: A comprehensive mass flux scheme for cumulus parameterization in large-scale models, Mon. Weather Rev., 117, 1779-1799, 1989.

Todini, E.: AFORISM - A comprehensive forecasting system for flood risk mitigation and control, Final report of Contract EPOCCT90-0023, 1995.

Todini, E.: Influence of parameter estimation uncertainty in Kriging, Part 1, Theoretical development, Hydrol. Earth Sys. Sci., 5(2), 215-223, 2001.

Todini, E. and Ciarapica, L.: The TOPKAPI model, in: Mathematical Models of Large Watershed Hydrology, edited by: Singh, V. P. and Frevert, D. K., Water Resources Publications, Littleton, Colorado, USA, 914 pp., 2002.

Todini, E.: Hydrological catchment modelling: past, present and future, Hydrol. Earth Sys. Sci., 11(1), 468-482, 2007.

Tomassetti, B., Coppola, E., Verdecchia, M., and Visconti, G.: Coupling a distributed grid based hydrological model and MM5 Meteorological model for flooding alert mapping, EGU, Advances in Geosciences, 2, 59-63, 2005.

Tribbia, J. J. and Baumhefner, D. P.: The reliability of improvements in deterministic short-range forecasts in presence of initial state and modeling deficiencies, Mon. Weather Rev., 116, 22762288,1988
US Army Corps of Engineers Hydrologic Engineering Center: HEC-HMS Hydrologic Modeling system user's manual, USACE-HEC, Davis, California, 188 pp., 1998.

US Army Corps of Engineers Hydrologic Engineering Center: Hydrologic Modeling system HEC-HMS, Technical reference manual, USACE-HEC, Davis, California, 157 pp., 2000.

US Department of Agriculture: Urban hydrology for small watersheds. Technical release 55 of the Nature Resources Conservation Service, US Department of Agriculture, Washington DC, USA, 1986.

von Storch, H. and Zwiers, F.W.: Statistical Analysis in Climate Research. Cambridge University Press, 494 pp., 1999.

Wilks, D.: Multisite downscaling of daily rainfall with a stochastic weather generator, Clim. Res., 11, 125-136, 1999.

Wilks, D. S.: Statistical methods in the atmospheric sciences. Second edition. Elsiever Academic Press Publications, International Geophysics Sciences, 627 pp., 2006.

Zhang, D. L. and Anthes, R. A.: A high resolution model of the planetary boundary layer, Sensitivity tests and comparisons with SESAME-79 data, J. Appl. Meteorol., 21, 1594-1609, 1982.

Zhang, D. L. and Fritsch, J. M.: Numerical simulation of the meso$\beta$ scale structure and evolution of the 1977 Johnstown flood, Part I: Model description and verification, J. Appl. Meteorol., 43, 1913-1943, 1986.

Zhang, D. L., Chang, H. R., Seaman, N. L., Warner, T. T., and Fritsch, J. M.: A two-way interactive nesting procedure with variable terrain resolution, Mon. Weather Rev., 114, 1330-1339, 1986. 